\title{
جماليات العرض المسرحي عند أدولف آبيا وإدوارد جوردن كريج
}

\author{
د/ مروة عبد العليم زلابية \\ مدرس الإعلام والمسرح التربوي- بقدم لإبية \\ الإعلام التربوي - كلية التربية النوعية- \\ جامعة المنوفية
}

أ.د / محمود همام عبد اللطيف

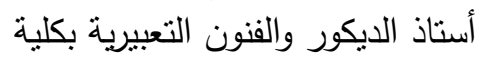

الفنون الجميلة والرئيس الأسبق لقسم

المسرح كلية الآداب - جامعة حلوان الأنيق

$$
\text { اخصائية تربية مسرحية- عادل عبدريه القرارة منوف }
$$

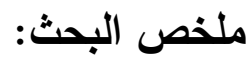

استهدف هذا البحث التعرف على جماليات العرض المسرحي عند أدولف آبيا وإدوارد جوردن كريج، وإعدادهما للمسرح بما يشمله من (ديكور ، إضاءة، ممثل، موسيقى) وتكامل هذهات

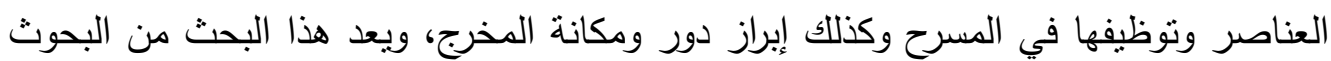
الوصفية، حيث قام البحث على المنهج التاريخي للتعرف على تاريخ تطور المسرح وحياة آبيا وكريج وأهم الملهمين في حياتهم، والمنهج المقارن للكثف عن نقاط الاتفاق والاختلاف بين منهج ونظريات آبيا وكريج، ونم استعراض جماليات العرض المسرحي لكل منهما وتأكيدها من وان خلال صور لتصميماتهما وتحليلها والتي نم الحصول عليها من خلال العديد من المراجع الأجنبية، وتوصلت نتائج البحث إلى أن جهود آبيا وكريج مهدت لتأسيس نظرية "المسرح المسرحي Theatrical Theatre وهي النظرية الني يقوم عليها مسرح اليوم، رؤية كريج للعديد من الصور لتصميمات آبيا قبل أن يقابله في زيوريخ، وتأثره بنظرياته قبل الإعلان عن نظرياته

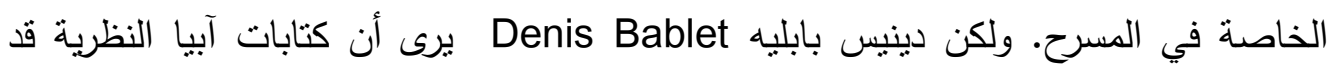
نشرت قبل كتابات كريج لكن لم يكن أي منهما على علم بأعمال الآخر ، كثيرًا من أفكار آبيا قد لدابه

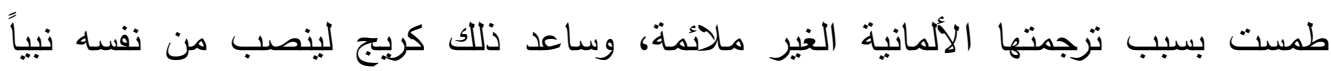

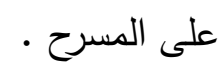




\section{Abstract:}

This study aimed at identifying the lest aspects of the theatrical performance of Adolphe Appia and Edward Gordon Craig and their preparing of the theatre including (decoration, lightening, actor and music) and the integration of these elements and employing them in the theatre and also showing the role and the position of the director. This study belongs to the analytic studies and its fram, the researcher used the historical method to know the history of the theatrical development and the life of Adolphe Appia and Edward Gordon Craig, the most important inspirators in their lives and the comparative mrthod to show the points of agreement and disagreement brtween the method and theories Appia and Craig. The finest points of the theatrical performance for both of them and conferming them through photos of their designs and analyzing them which had been obtained through several foreign referances. The study results found that The efforts of Appia and Craig has paved the way to setup the theory of "theatrical theatre" and it is the theory on which the theatre of today, Craig's looking at a lot of Appia's designs before meeting him in Zurich refeers to seeing Appia's paintings and his influence with his theories before announcing his private theories in the theatre. But Denis Bablet sees that Appia's theatrical writings had been published before Craig's writings but no one of them had known the works of the other, Alot of Appia's ideas disappeared due to the unsuitable German translation, and this helped Craig set himself up as a prophet on the theatre. 
مقدمة:

تعرف المسرح على العديد من الاتجاهات المسرحية الحديثة، من هذه الاتجاهات ما لقى

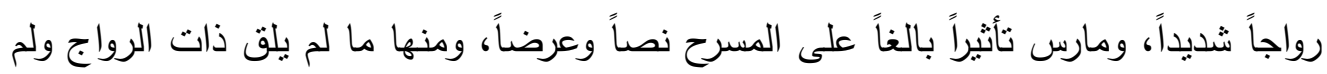

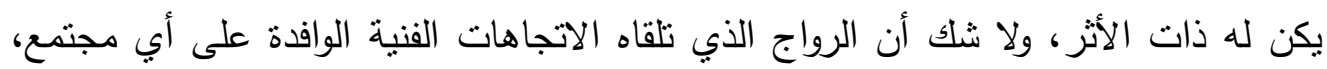

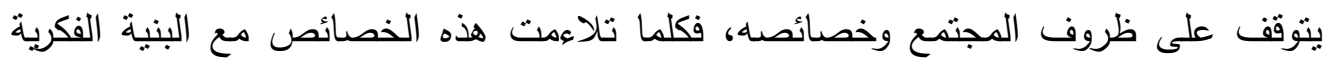

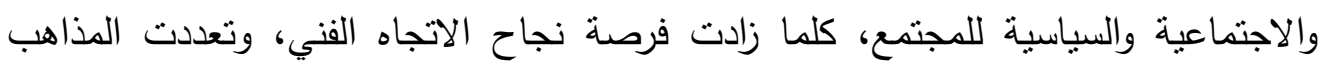
المسرحية وتتوعت على مر العصور ومن أنثرها المدرسة الرومانسية التي ظهرت في القرن التاسع عشر وروادها فيكتور هيجو، ألسكندر دوما، ألفرد دو موسيه وجوته وينطلق هذا المذهب من فلسفة جان جاك روسو الداعية إلى العودة إلى الطبيعة والثثورة على مجتمع المدنية والفساد. المدرسة الطبيعية ظهرت مع إميل زولا وتهتم بنقل الأحداث كما تقع في الطبيعة ودراسة آلياتها مع التحكم فيها من خلال تغيير العوامل المكانية والظرفية دون إبعاد قوانين الطبيعة، فكانت المسرحيات تقدم الحياة في ثوبها الطبيعي ولكن بطريقة فنية وكانت كل

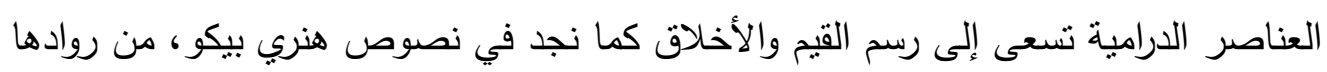

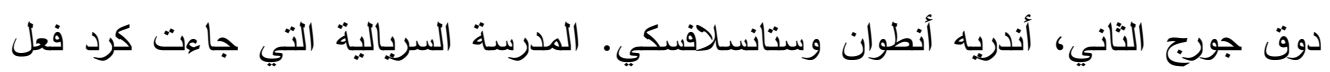

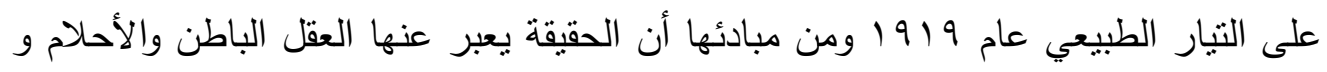
ذللك بالتحرر من سيطرة العقل والوعي والمنطق وروادها أندريه برينون، لويس أراغون وفيليب

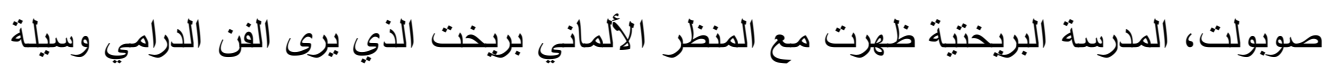

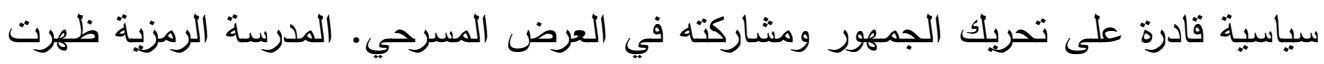

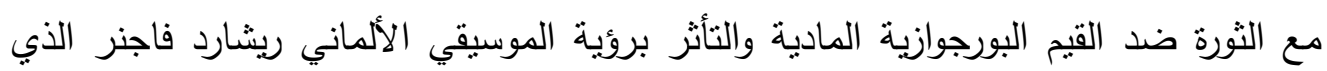
كانت لآرائه أثر كبير في المسرح مما ساهم في ظهور تيار أدبي رمزي يدعو إلى استعمال

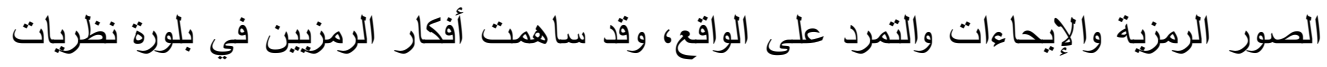

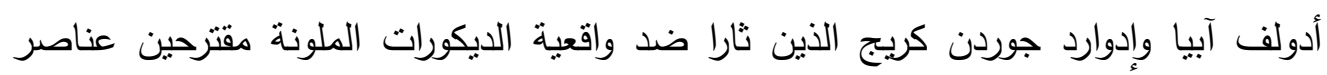
موحية ومجردة مع استعمال لعبة الإضاءة لخلق الانطباعات بدل الإيهام بالواقع

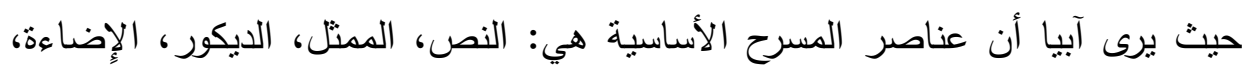

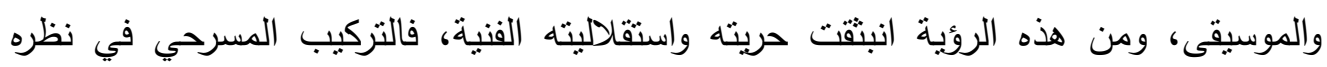
وحدة وانسجام، فالموسيقى هي العنصر المهم الذي يساعد على تحقيق هذا التركيب، والديكور

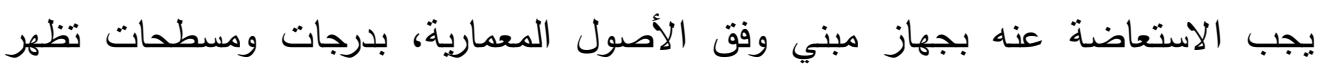


حركات الممنل في جميع قدراته التعبيرية. صار على مسار أستاذه وملهمه فاجنر في اهتمامه بالإضاءة، حيث يعتبر الإضاءة من الوسائل التي تعطي للمكان والممثل قيمة تشكيلية كبيرة،

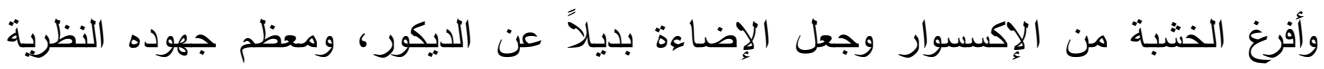

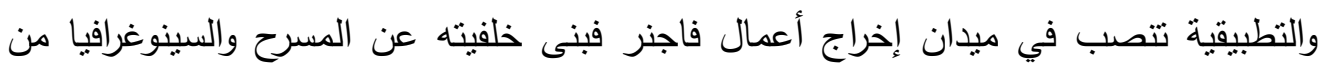
منطلق كونه مشاهد للاراما الموسيقية الفاجنرية في معظم حياته الإبداعية، وصمم الكثير من إعن

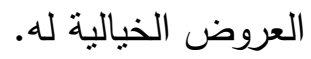

أما كريج كانت نظريته في الفن المسرحي ممثله في تصميماته التي اعتبرت نهضة بإحيائها للمسرح الإغريقي القديم ومسرح القرون الوسطي والمسرح الياباني والهندي بكل معاني البساطة والسمو التي تتصف بها هذه المسارح، وقد ثار علي الممثل واستعاض عنه بالإمي ولئي المتحركة لاعتقاده بأنها أكثر صدق وطواعية ولن نتتازل عن أهدافها بسهولة أمام ديكتاتورية المخرج، كما تخلص من الكوالبس وكافة الزوائد الخلفية والستائر وقطع الديكور التقليدية والمناظر المرسومة في عمق المسرح فقد اعتمد في مؤثراته المسرحية علي مزيج من الفراغ

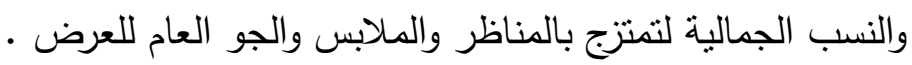
والمقارنة بين هذين المبدعين أمر ضروري وهام نظراً لجهودهم في إدخال مفاهيم جديدة

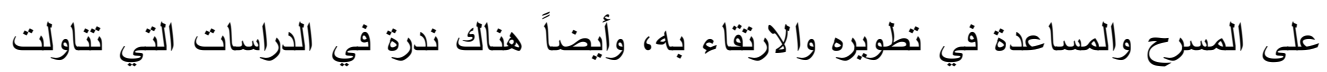

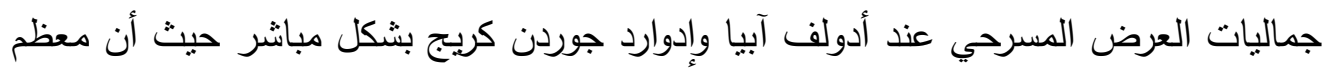
الدراسات تتاولته في عينة الدراسة أو جزء من الدراسة وليست دراسة كاملة الئة

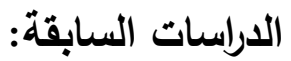

المحور الأول: دراسات تتاولت العرض المسرحي:

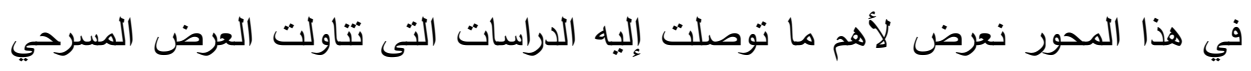

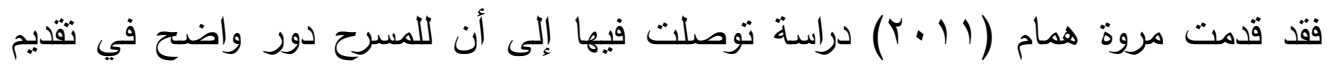
الموروث الثعبي وترسيخ مفهوم العادات والتقاليد التي بدأت أن تتدثر ويحل مكان لثانها النقافات الوافدة إلينا من الغرب، والموروث الثعبي مادة غنية بالإرث الثقافي والإبداعي يفتح آفاق

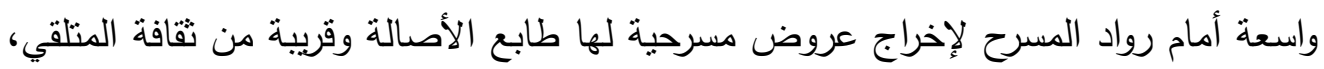

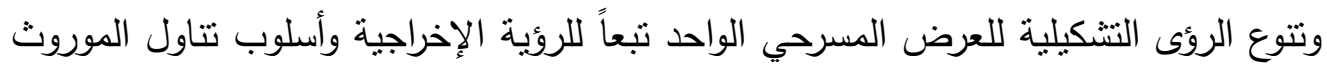

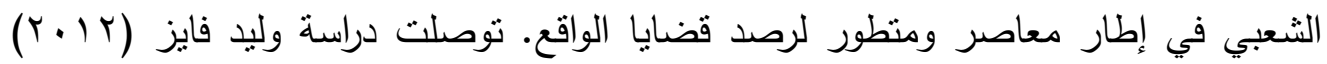

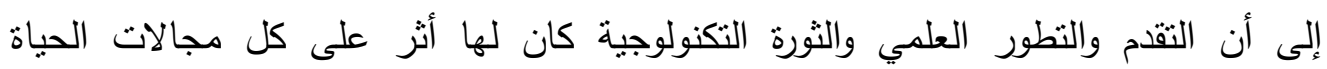


وبخاصة شقي البحث سواء التصميم الداخلي أو ديكور المسرح، ولقد ظهرت العديد من المصطلحات المسرحية الحديثة والتي كانت غير معروفة أو مألوفة لدى المسرحيين القدامى الدى ولئي كمصطلح السينوغرافيا والذي يظل كمصطلح مبهم عربياً حتى الآن على الرغم من ظهوره

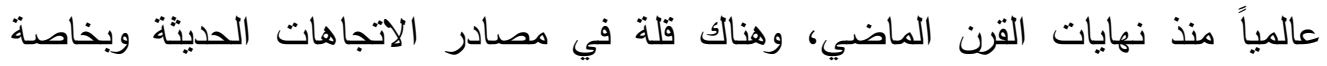

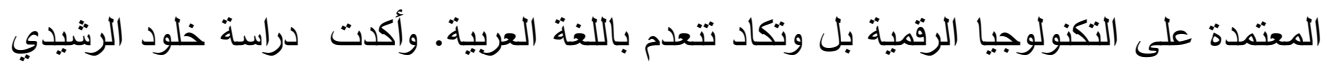

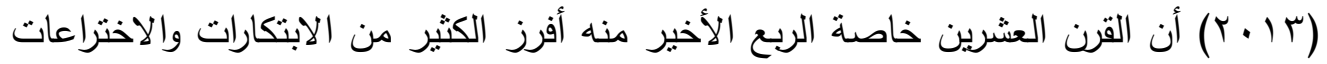

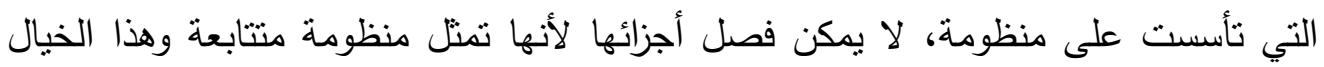

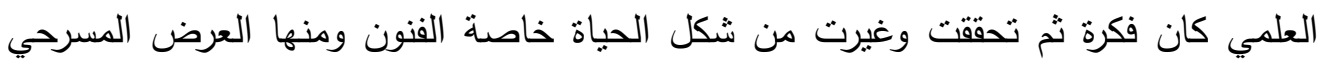
المقدم للأطفال المستتد على قصص وأحداث تكنولوجية ومبادئ علمية، والميكانيكا كأحد

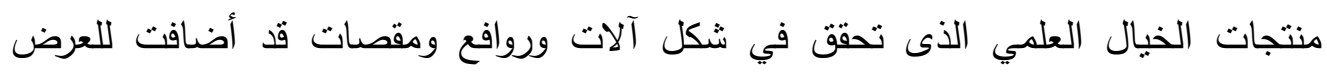

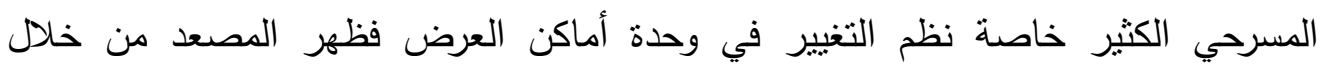
المحرك الكهربائي والضغط والأوزان ونظام الكباسات الهيدروليكية وطرق الانزلاق والتحريك

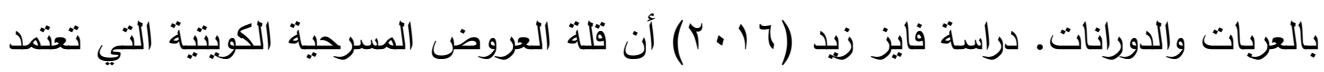
على الارتجال، والعروض المسرحية الكويتية التي اعتمدت على الارتجال كانت لمجرد الضحك فقط.

المحور الثاني: دراسات تناولت أدولف آبيا وإدوارد جوردن كريج: توصلت دراسة وحيد فوزي (• (†) إلى أن الفراعنة بمفهوم العصر الحديث للمسرح المفتوح، استخدموا كافة الفراغات المتاحة من معابد وطرقات ومواكب نيلية وساحات المعابد، وقدم المسرح اليوناني والروماني مثالين جيدين لتشكيل الفراغ في المسرح المفتوح، وتقلص دور

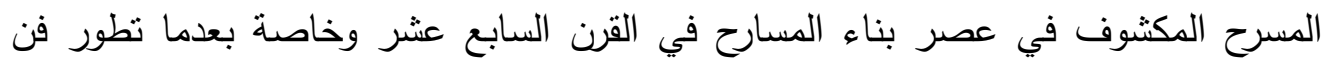
المنظور في المسرح وأصبح فناً تقام على إثره العروض والمشاهد لتبهر المشاهدين بكيفية

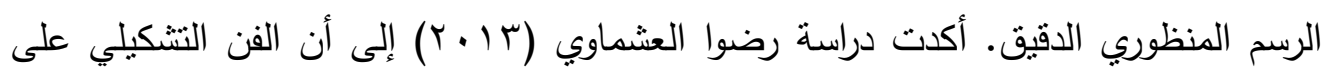

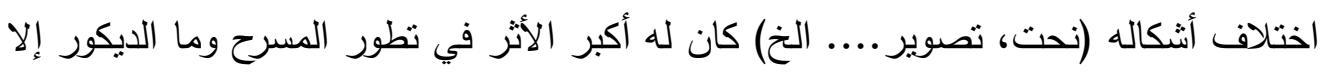
شكل من أشكال الفن التشكيلي ولكن بصورة وظيفة مختلفة وبذلك فإن طريقة إقحام العمل التتكيلي لم تعد عبارة عن نزيين للفراغ بل أصبحت رفض لجمود خشنبة المسرح، والمناظر

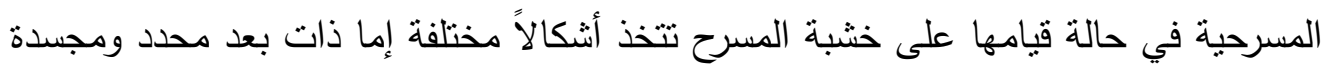
أو أنها مرسومة أي مسطحة، ولقد شهد القرن العشرين أكثر الفترات في التاريخ الفني ثراء 
بالفنانين الذين مارسوا فن تصميم المناظر ـ أوضحت دراسة بسنت عبد الحميد (10 • ؟) أن

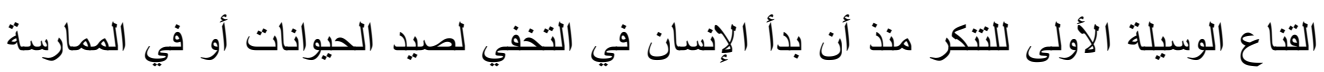
الطقوسية، إلى أن استخدم في تتكر فناني المسرح لتقمص بعض الأدوار للثخصيات

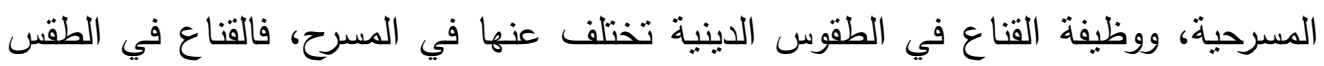
الديني يستتد إلى فكرة التمثيل الرمزي للآلهة، أبي أنه يعتبر وسيلة تؤدي إلى غاية، ويمكن أنى أن يكون هدفاً في حد ذاته.

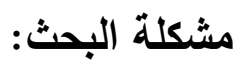

مر المسرح كفن شامل بالعديد من النظورات النظرية والعملية على يد المنظرين من

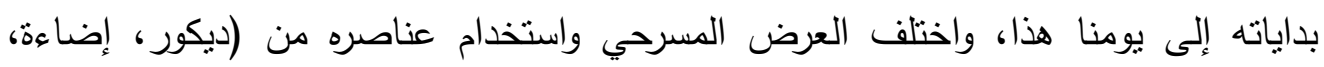

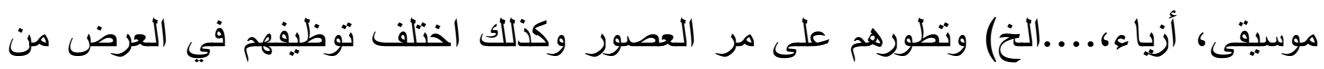
مذهب إلى آخر ، ويعد من أثنهر هؤلاء المنظرين الذين أدخلوا مفاهيم جديدة في الإضاءة والديكور المسرحي أدولف آبيا وإدوارد جوردن كريج، لذلك وجب عنداء على الباحثة عمل دراسة

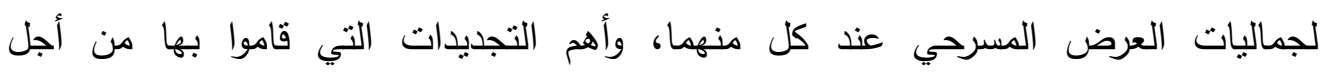
تطوير المسرح. من خلال الاطلاع على الدراسات السابقة لاحظ الباحثون قلة الدراسات التي تتاولت جماليات العرض المسرحي عند أدولف آبيا وإدوارد جوردن كريج، وتللك الدراسات الني تناولت آبيا أو كريج تتاولتهما بشكل غير مباشر وكانا ضمن جزء من عينة الدراسة وليست دراسة

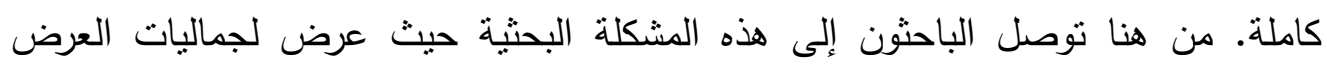

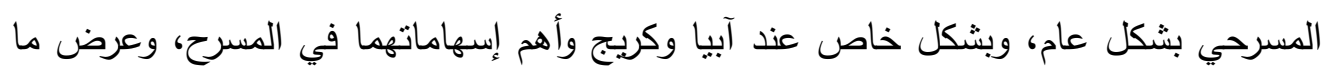

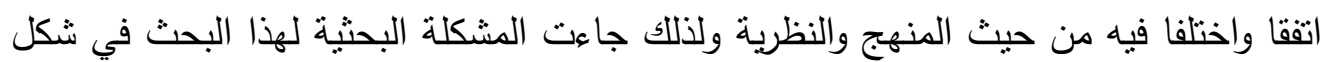

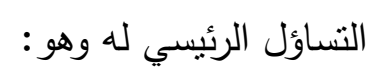

ما جماليات العرض المسرحي عند أدولف آبيا وإدوارد جوردن كريج؟ : إنها : وانبثق منه عدة تساؤلات فرعية كالآتى:

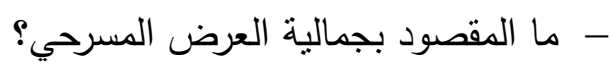

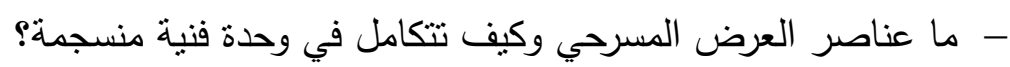

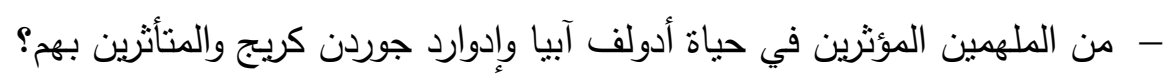
- ما مفهوم المسرح عند آبيا وكريج؟ 


$$
\begin{aligned}
& \text { - ما مكانة ودور المخرج عند آبيا وكريج؟ } \\
& \text { - ما الأفكار التي نادى بها آبيا وكريج لنطوير المسرج؟ وكرج؟ }
\end{aligned}
$$

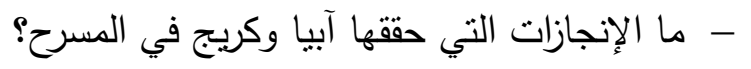

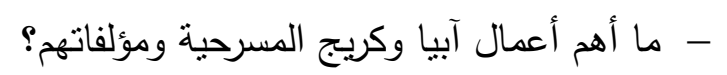

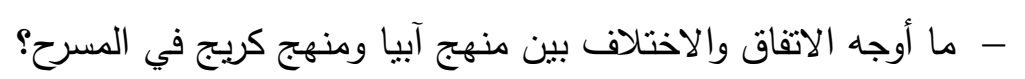

$$
\begin{aligned}
& \text { أهمية البحث: ماته التفاق }
\end{aligned}
$$

- عرض عناصر العرض المسرحي وأهمية نوظيفها في المسرح بما بساعد في تطوره فسيهتم به العاملين بمجال المسرح. - أدولف آبيا وجوردن كريج من أعظم مخرجي المسرح ويجب الاستفادة من نظرياتهم ومنهج

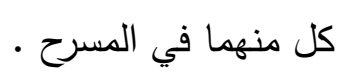

- عدم وجود عروض مسرحية لأدولف آبيا وجوردن كريج يمكن مشاهدتها وتحليلها، وعدم

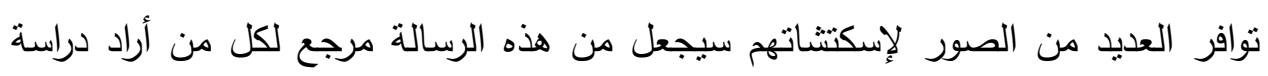
أعمالهم ونظرياتهم.

- الاعتماد في الدراسة على العديد من المراجع الأجنبية وترجمتها يزيد من أهميتها وسط

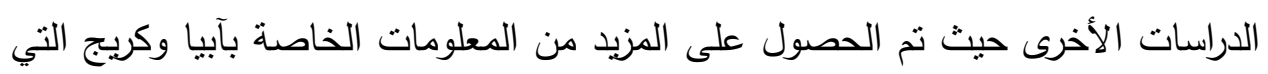

$$
\text { لم تكن موجودة في أي من الكتب والدراسات العربية. }
$$

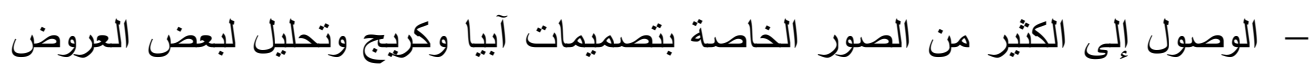
من خلال الكتب التي قاما بتأليفها وذللك بضمن سلامة المعلومات والتأكد من صحتها.

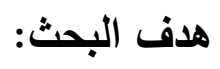

$$
\text { يهدف البحث الحالي إلى : }
$$

- التعرف على عناصر العرض المسرحي وكيفية تكاملها وتوظيفها بشكل يخدم العرض إله

$$
\text { وبرتقي به. }
$$

- التعرف على حياة أدولف آبيا وإدوارد جوردن كريج والمأثرين فيهم والمتأثرين بهم.

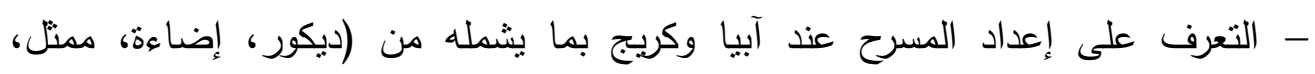
موسيقى) وتكامل هذه العناصر وتوظيفها في المسرح. - توضيح دور ومكانة المخرج في مسرح آبيا وكريج. 
- عرض أهم الأفكار التي نادى بها آبيا وكريج وإسهاماتهم في المسرح. - التعرف على أعمال آبيا وكريج المسرحية ومؤلفاتهم. - التعرف على أوجه الاختلاف والاتفاق بين منهج آبيا ومنهج كريج.

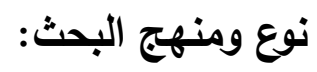

ينتمي البحث إلى الدراسات الوصفية، واعتمد البحث على المنهج التاريخي للتعرف على تاريخ تطور المسرح وحياة أدولف آبيا وإدوارد جوردن كريج وأهم الملهمين في حياتهم، والمنهج

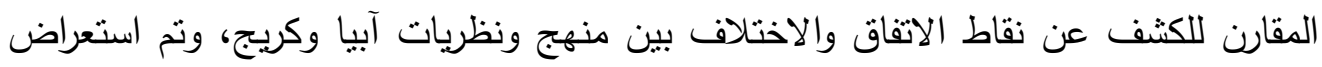

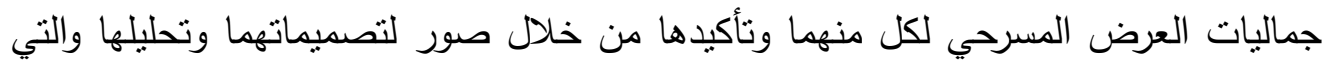
تم الحصول عليها من خلال العديد من المراجع الأجنبية.

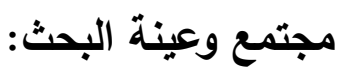

تتمثل عينة البحث فيما تمكنت الباحثة من الوصئه البحت إليه من نقد فني ومسرحي لأعمال كل من

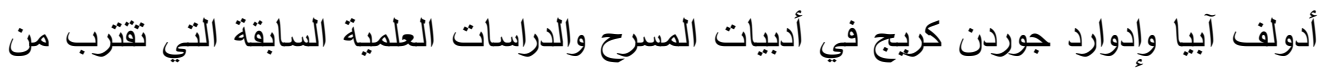
هذا الموضوع، وصور التصميمات الخاصة بهم وتحليلها.

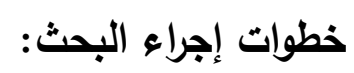

ا. دراسة وتحليل الدراسات والبحوث السابقة المرتبطة بعناصر العرض المسرحي، وكذلك جماليات عناصر العرض عند آبيا وكريج.

r. جمع المادة العلمية الخاصة بموضوع البحث وتحديد المحتوى الملائم لمتغيرات البحث.

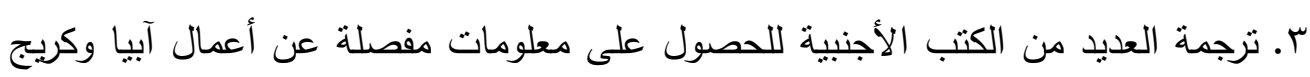
وإنجازاتهم في المسرح وكذلك الوصول إلى الكثير من الصور الخاصة بتصميمات آبيا وكريج وتحليل لبعض العروض من خلال الكتب التي قاما بتأليفها وذلك لضمان سلامة التهن المعلومات والتأكد من صحتها.

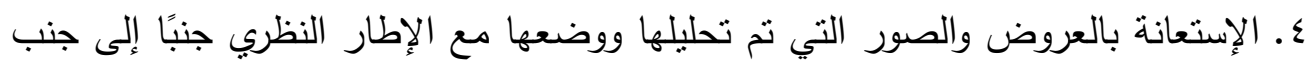
لتأكيد جماليات العرض المسرحي عند كل منهما. ه. كتابة فصل يجمع بين آبيا وكريج وعن أول مقابلة لهما في زيوريخ، وعرض الخدان الخصائص الفنية لكل منهما والتي اتفقا في بعضها واختلفا في البعض ولته الآخر . T. Y. عرض النتائج وتفسيرها ومناقشتها. V. تقديم التوصيات والمقترحات على ضوء النتائج التي تم التوصل ومنافئه إليها. 


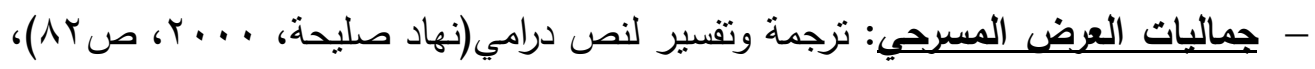
وتحويل هذا النص إلى منظومة متتاغمة من المؤثرات المرئية والصوتية التي تحتوي دري

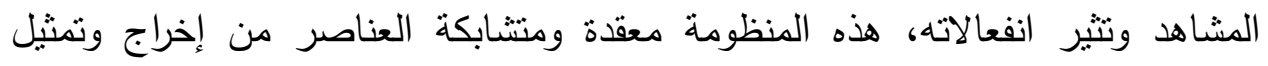

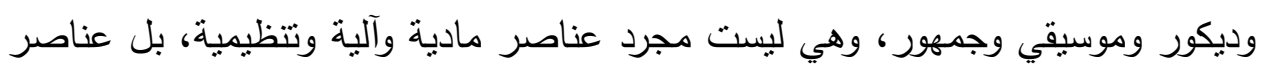

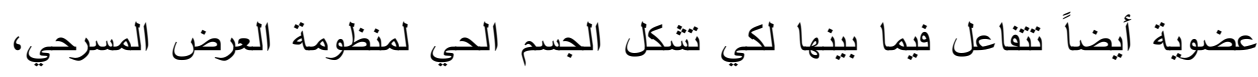
وبدون هذا التقاعل لا يوجد مثل هذا العرض، بل لا يوجد فن المسرح على الإطلاق(نبيل

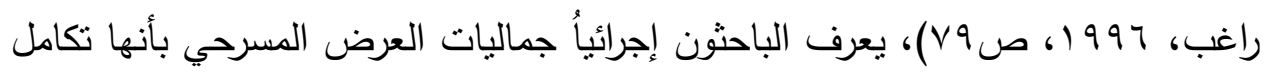

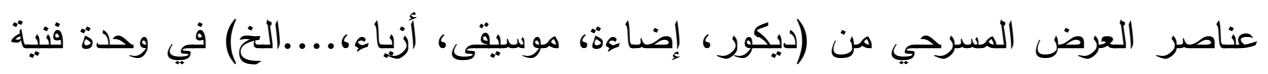

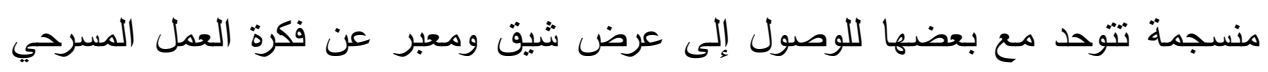
وتتبه أوركسترا العرض الموسيقي في تتاغمها، وجمالية العرض المسرحي ونجاحه تظهر من خلال رد فعل الجمهور الذي شاهد العرض ومن تعليقاته وانفعالاته ومدى تأثره

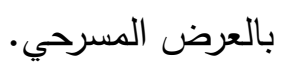
- الرمزية: هي التعبير عن الأفكار والعواطف والإيحاء بها عن طريق الرموز، قد تكون

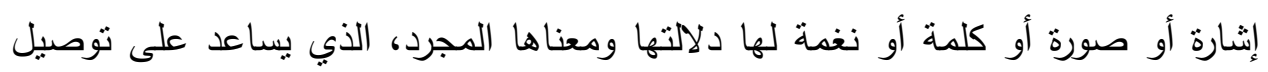
المفهوم والمزاج النفسي، وقد شهد المسرح رجالاً أفرغوا كل جهدهم في تأكيد الرموز في المهاء

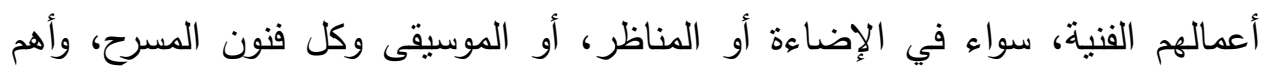

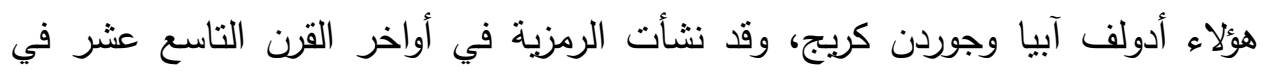
فرنسا، حيث جاءت بأفكار جديدة معادية للواقعية والطبيعية، وعلى صعيد الإخراج

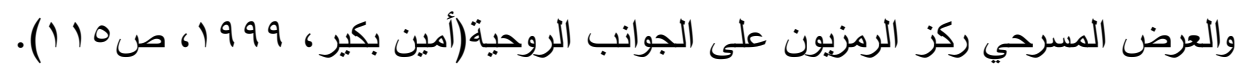

\section{جمالبات العرض المسرحي عند أدولف آبيا :}

إن العمل المسرحي قائم على ثنائية نص وعرض، المسئول عن النص هو شخص واحد

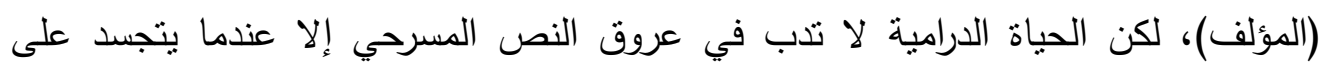

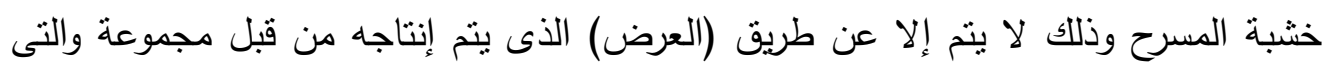

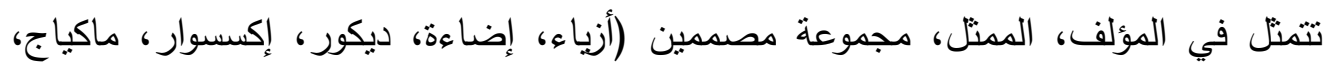
موسيقى) والمخرج وهو المسئول عن جميع عناصر العرض المسرحي ومسئول عن نكاملها لخلق تركيبًا فننيًا جماليًا. 
إهتم آبيا بالممثل ورأى أن الخداع المسرحي هو قوة إنثعاع الممنل على خثبة المسرح،

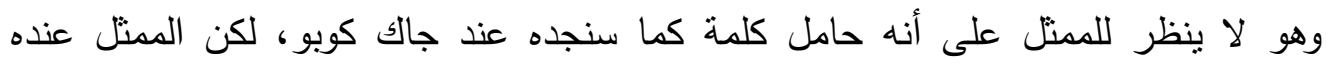
عنصر من عناصر التركيبة الثاعرية، الناتجة من التقاعل بين حركة الجسم الحي، وحركة

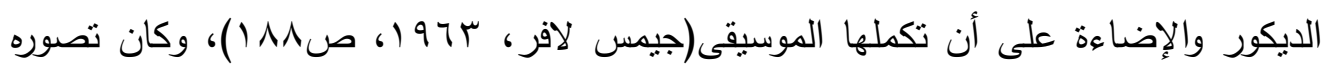
يعتمد على إدخال الجمباز الموسيقي في فن التمثيل لتصبح الموسيقى هي التي تتحكم بتعبير

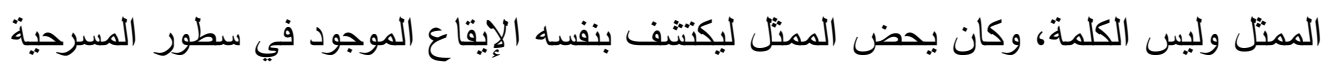

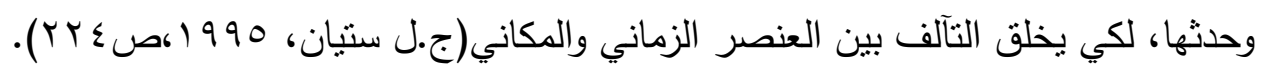

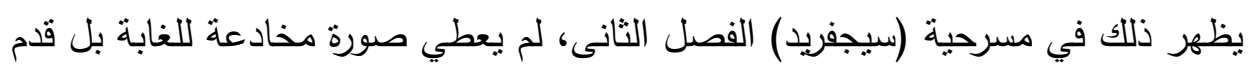

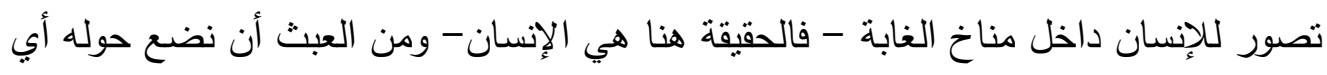
عناصر خداع (فالديكور تصور فلسفي ينبع من عنصرين تشكيلين "التصوير" من خلاد النور

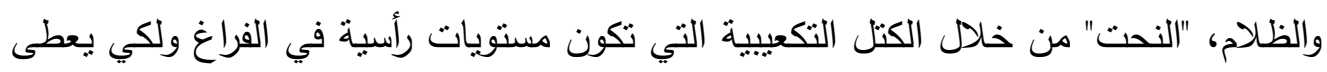

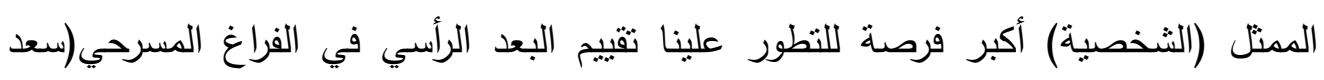

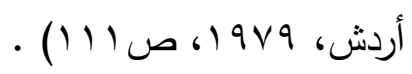

والأداء الصوتي للممثل بالنسبة له هو المعادل لصوت الممثل المغني والموسيقى في الأوبرا، وهذا يزيد من أعباء الممثل لأنه سيقتضيه إهتماماً خاصاً بالجوانب الموسيقية في أدائه

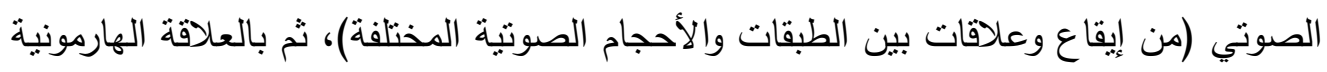
بين الصورة الصوتية والصورة الحركية، ثم علاقة كل ذلك بالمناخ الذي يتحرك فيه أفقياً ورأسياً داخل الديكور المشيد من براتيكابلات وسلالم ومصاعد ومهابط ومن ألوان وظلال(سعد أردش،

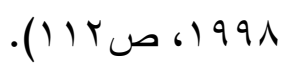

ويتضح ذلك في الفصل الثالث من مسرحية (سيجفريد) المشهد الأول عندما تتزل النار من صخرة الفالكيرات ويتزايد تهديدها بالخطر وتتشأ عن الكثف الخلفي التدريجي عن أجزاء الجبل التي تمثل نارًا مندلعة وقد رسمت رسماً شفافاً هنا تكمن القضية إما الممثل إما الرسم.

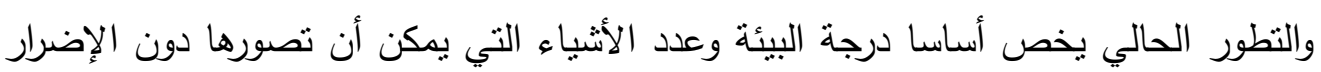

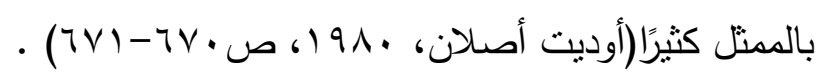

يعتبر في مقدمة المتحمسين الثائرين على الإتجاه الواقعي في المناظر المسرحية، حيث يشكل إتجاهه الجديد ثورة في إيجاد الطريق الحديث لمفهوم المناظر المسرحية، فكل مناظره مرسومة ومضمونة بحيث تسير في نوافق وإنسجام مع الممثل ذي الأبعاد الثناثة الذي يتحرك 
داخلها، وقد أكد وجود الدرج والمستويات والأعمدة والمعلقات المنسجمة للخطوط باعتبارها

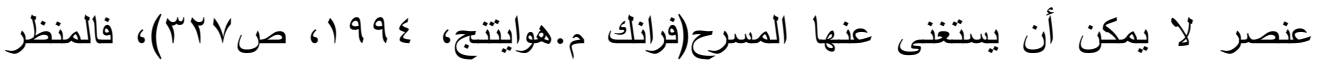

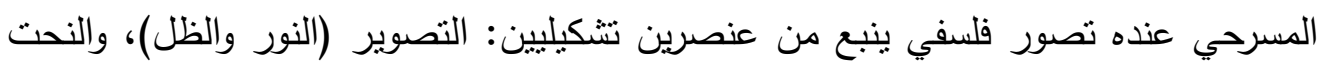

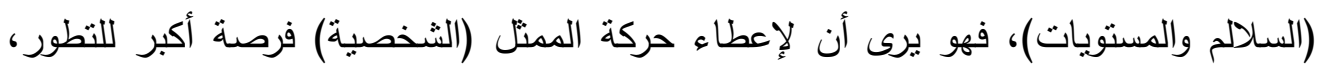
يجب ألا يتحرك على أرضية مسطحة، بل داخل تركيب من السلالم والمنحدرات وهو ما يمكن لإن إنه أن نعبر عنه بتقييم البعد الرأسي في الفراغ المسرحي، وهو بعد ذللك يلجأ إلى التصوير ولكن

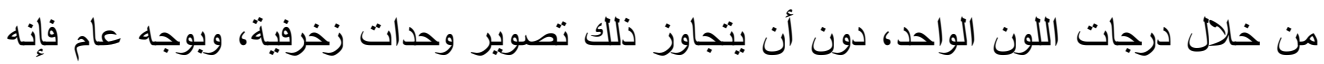

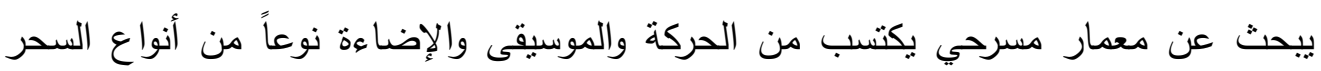
الذي يوحي بالمناخ النفسي والحسي للصراع الدرامي(سعد أردش، 9 (9 (1)، ص (1) (1). وظهر تأثره بالرمزية بوضوح في تصوره للايكور المسرحي في مسرحية (بروميثيوس)

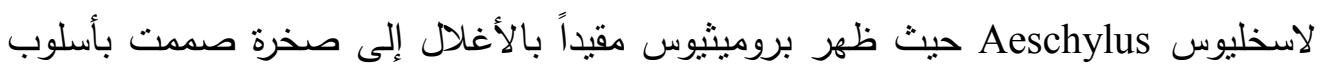

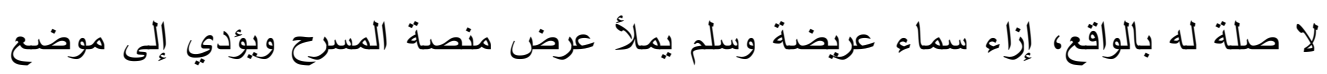

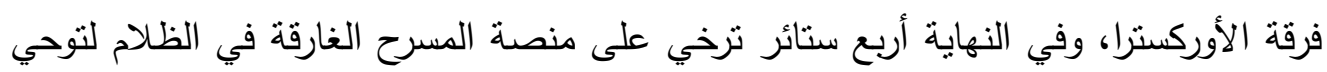

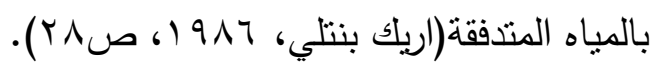
كان تركيزه على الوحدة العضوية للمنظر المسرحي وتكامله، والتركيز على المعاني والدلالات التي تعطيها الصورة المسرحية للمشاهد، وكان يعتمد على الإضاءة في التحويل بين

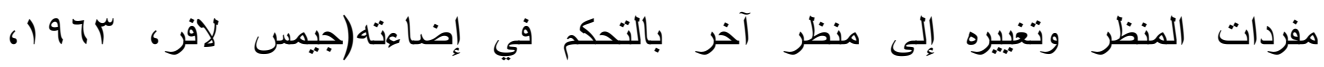

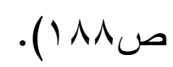

ويظهر ذللك في مسرحية (تريستان وإيزولده) عند رفع الستارة تظهر شعلة كبيرة وسط المسرح، المسرح مضاء حيث يمكن التعرف بوضوح على الممثلين، يوجد بعض الخطوط التي

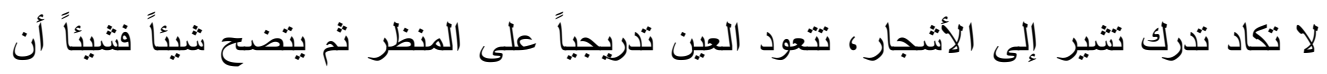

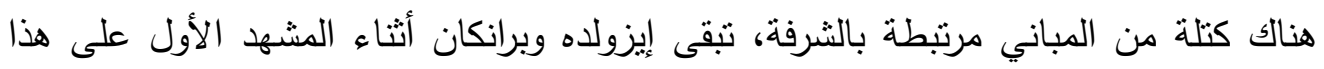

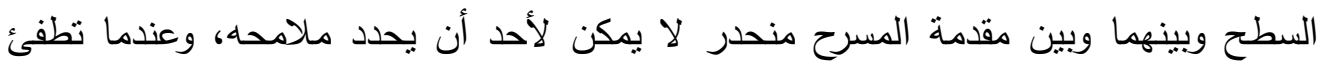
إيزولده الثعلة يظهر ضوء شاحب لا نستطيع العين معه أن تميز شيئاً، تتطلق إيزولده

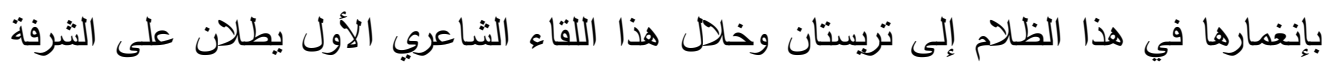

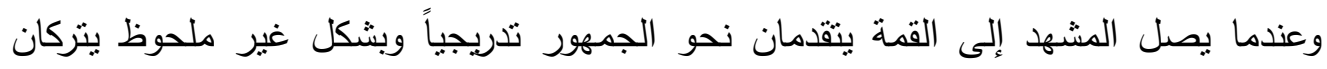

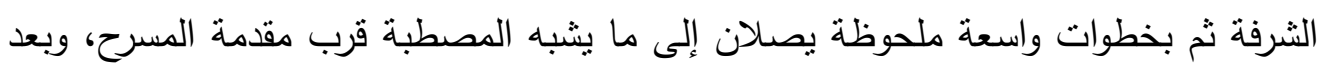


أن تهندأ لهفتهما بعض الثيء وتربطهما فكرة واحدة وعندما نكون في طريقنا لإدراك موت الزمن يصلان أخيرًا إلى أقصى مقدمة المسرح حيث نلحظ لأول مرة أن هناك مقعدًا

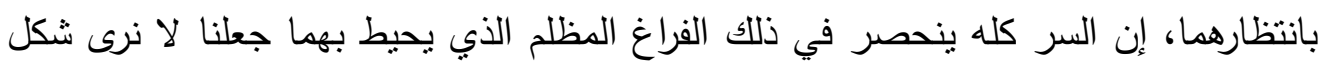

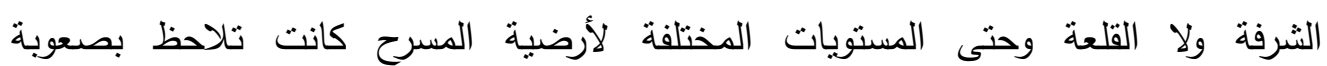
(Lee Simonson, 1932, p.362-363) يرى أنه لا يجب أن نصب الإهنمام باللون والدهان على حساب وضع الديكور ، ويعارض هذا التيار الذي كان قد ظهر في العصر الفاجنري، لأنه لم تكن الدراما بحاجة إلى الإنى الإنهام

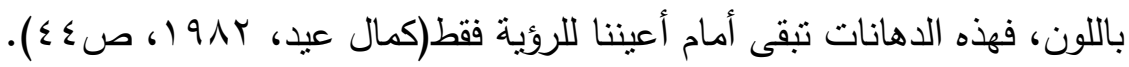

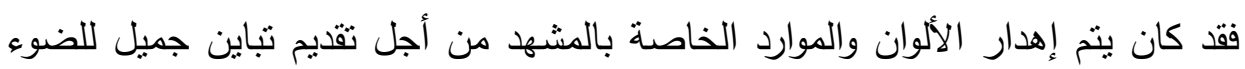

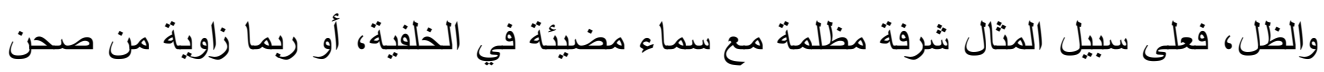

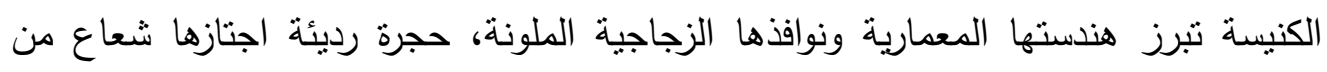

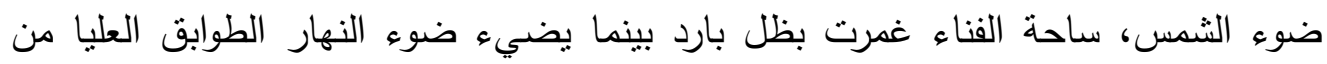

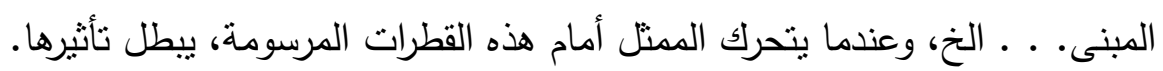

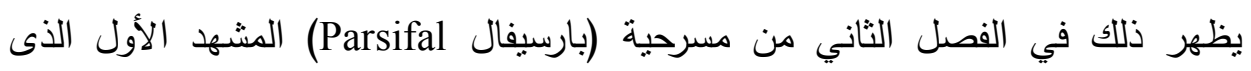

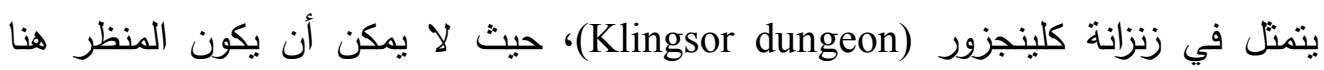

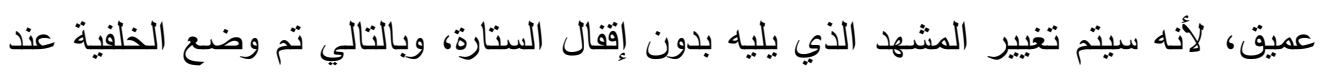

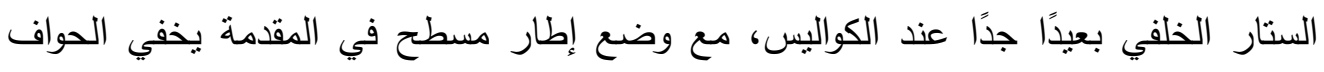
والأجنحة، هذا الترتيب كان مناسب للعب بالإضاءة التعبيرية، ثم أعطى السطح في المقدمة دورًا إيجابيًا في تركيبه وذلك عن طريق تحميلهم بتفاصيل مشهدية رائعة. نتج عن هذا الاتحاد

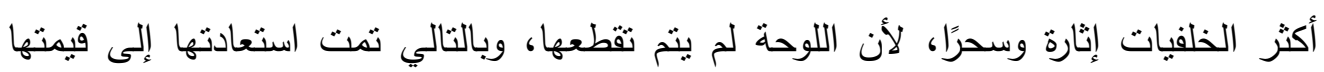
الأصلية. لكن الممثل ضاع هنا أكثر من أي وقت مضى لأن وجوده مقابل تأثير المنظر أبعد

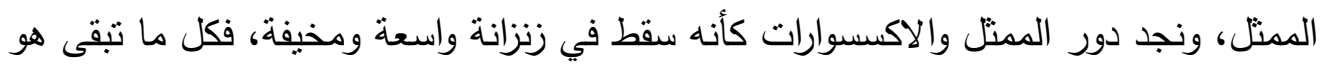
بعض اللوحات الزيتية المرسومة والمدهونة ببراعة. الساحر الثرير أصبح مجرد دمية وتمثيله

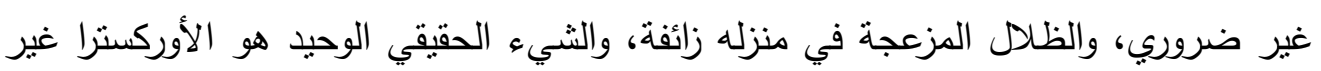
المرئية التي تدوي في الفراغ(Adolphe Appia, 1962, p.62). يرى أن الإضاءة المسرحية عنصر درامي فني حي متجدد، ويعد أول من وضع نظريات

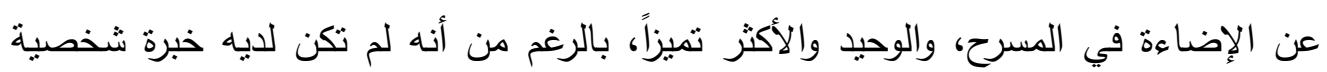


بالمسرح، وتربيته كانت بعيدة تماماً عن عالم المسرح المحترف(كريستوفربو، 9 9. ؟ب، صلV乏 ()، يعود الفضل له في إكتشاف الإمكانيات الدرامية والجمالية الكامنة لإستخدام

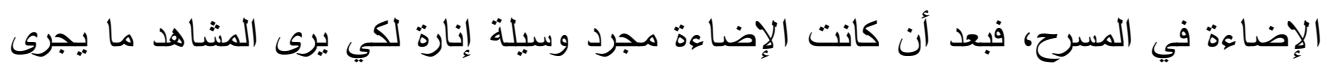

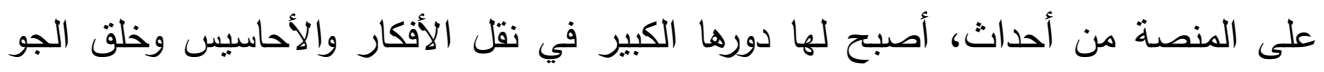

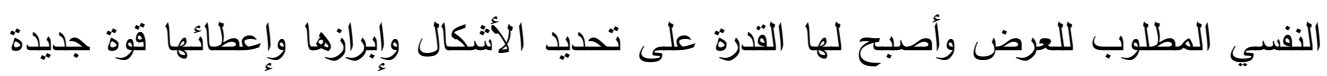
ومعنى جديد، ومازالت الكثير من الفروض التي وضعها نستخدم كقواعد نظرية وتطبيقية حتى ولى

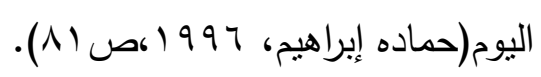

أضاف إلى الإضاءة فكرة عرض الصادم إلى بإستخدام ما بطلق عليه اليوم Gobos قدمتها الموسيقى، حيث أن الضوء المنضبط والموجه هو النظير المتمم للمقطوعة الموسيقية،

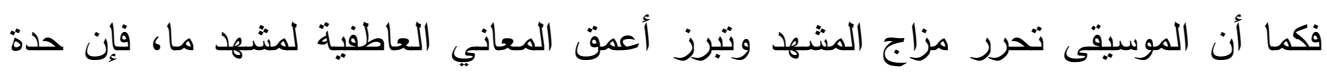

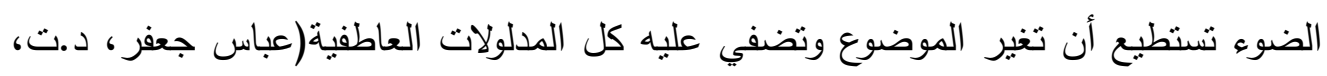

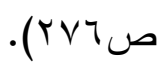
يظهر ذللك في الفصل الثاني من مسرحية (تريستان وإيزولده) عندما ندخل إيزولده نرى شيئين فقط: المشعل المضيء كرمز لتريستيان، والفراغ المظلم حوله، فهي لا نرى حديقة القلعة

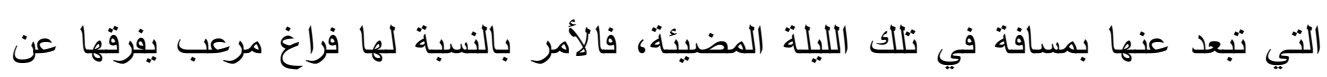

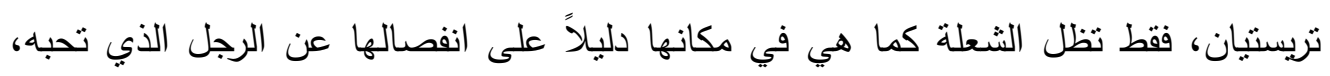
تطفئها في النهاية فيقف الزمن دون حركة، يتوقف الزمان والفراغ وأصداء العالم الطبيعي

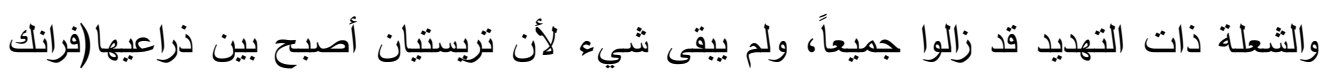

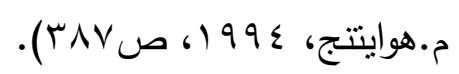

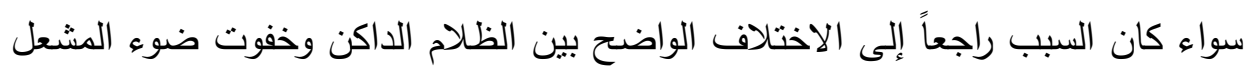

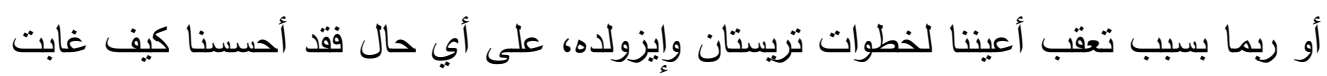

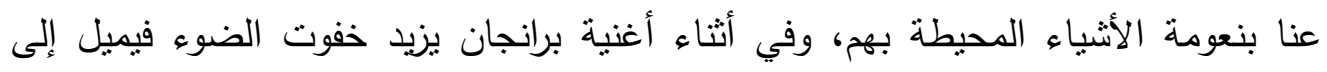

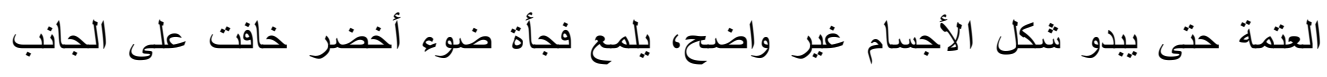

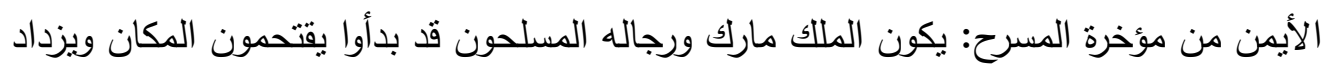
ببطء ضوء النهار البارد الذى لا لون له فتبدأ عين المتفرج أن تميز حدود المنظر ويبدأ لونه بالظهور بكل ما فيه من خشونة حينئ يسيطر تريستان بعد جهد كبير على نفسه ويدرك أنه 
بعد كل هذا على قيد الحياة فيتحدى ميلوت ويدعوه للمبارزة، لا شيء يغلف المكان البارد اللون

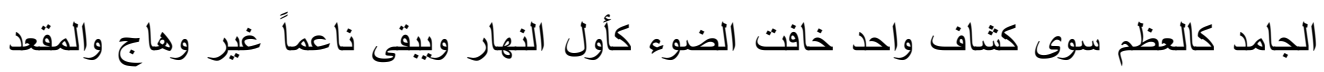
الخشبي عند أسفل الشرفة(Lee Simonson, 1932, p.362-363). تظهر نظريته في تصميم المشهد، وكيفية خلق فراغات لها مدلولات درامية وتتكيلية، في تصميم مسرحية بارسيفال Parsifal يقصد بالأشجار عندما تضاء من الخلف ويصبح الفراغ كتلة، أثجار الغابة المقدسة، وعندما يستخدم عنصر الإضاءة من الأمام ويقوم بإظلام الخلفية

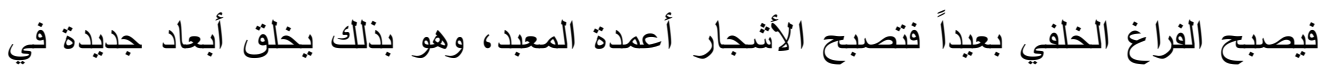

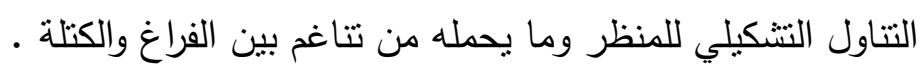
صار على مسار أستاذه وملهمه فاجنر حيث يعتبر الإضاءة من الوسائل التي تعطي لتئي

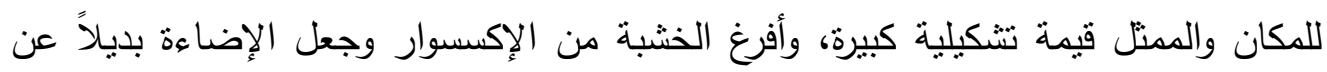

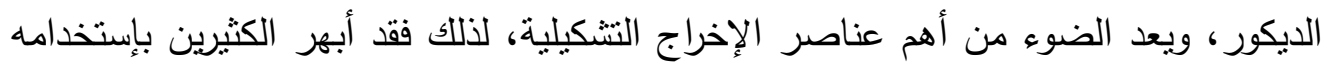
(سلايدات زجاجية ملونة) لإبراز الصور وفق وحدة ضوئية معينة، كذلك تغيير بيئة المكان من الإحراج

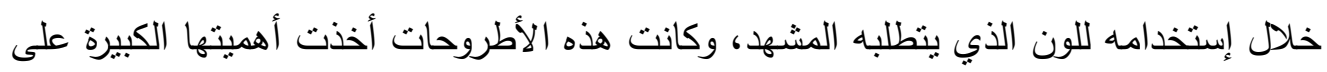
الممثل الذي إستطاع من خلال الألوان ومساقط الضوء الوصول لروح الثخصية التي يمنلاها، وتحسب له أهمية إستخدامه للإضاءة المسرحية بأسلوب فني ولازال بطبق حتى اليوم، ويقال

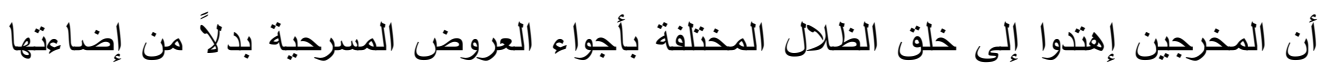

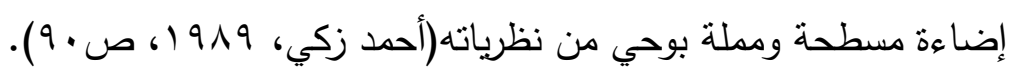
فلقد كان الضوء بالنسبة له رسام المشاهد الأسمى، فقد كان الضوء ذهاتهاء ذا قيمة بالقياس إليه

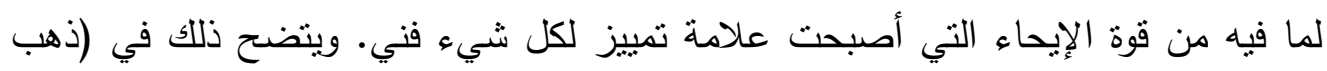

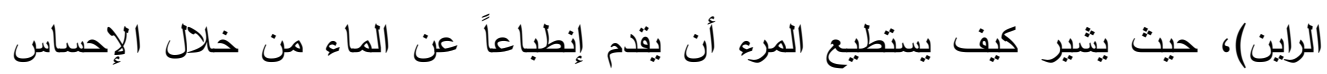

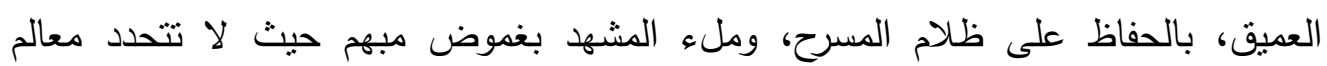
الأثخاص، وفي (Die Walkure) الهواء الطلق لا يمكن أن بحس به إلا إذا كانت قمة الجبل

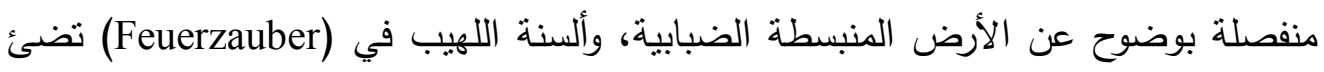

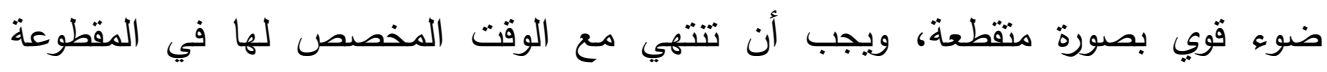
الموسيقية، أما الضوء في كهف البيريش فهو يستمد شعاعه من موقده فلابد أن تكون نوعيته مختلفة تماماً، حيث يعطي إحساساً بضيق وضآلة الضوء، وفي مسرحية (سيجفريد) فالدفين

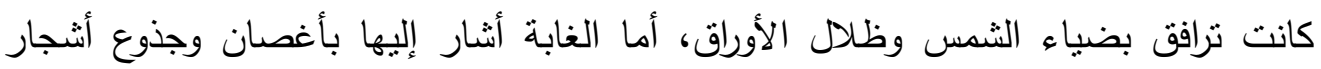


قللة، وبذللك يرينا أن إنسيابية الإضاءة المسرحية تتناسب مع كل حركة يقوم الممثل بها، حيث

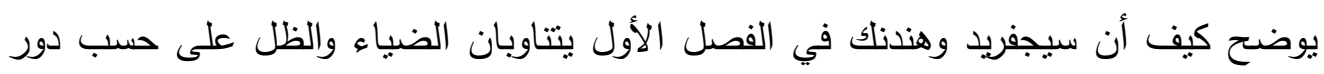

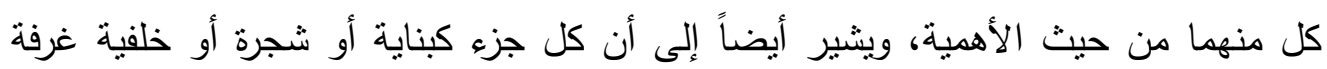

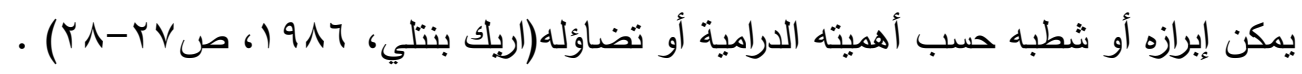
ظهرت موهبته في الموسيقى في سن مبكر ، فالموسيقى كانت الفن الذي اختاره، فقد كان يحصل

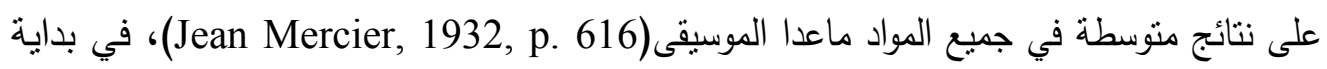
حياته ركز على الموسيقى كروح للاراما ولكنه تحول بعد ذللك إلى التركيز على الجسد الإنسانى

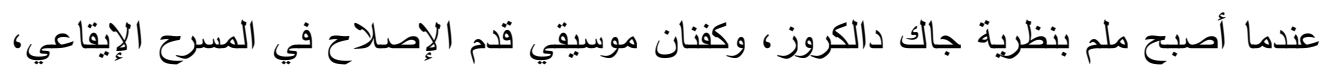

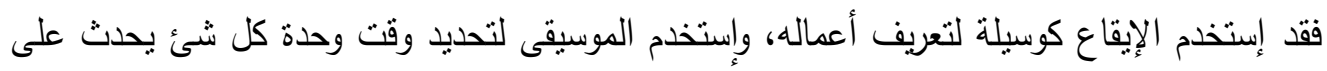

المسرح، فهي نعطي إيقاع موحد للعناصر المسرحية(Mahmoud Hammam, 1988, p.42). ألف العديد من الكتب عن الموسيقى منها : (الموسيقى وفن المسرح، الموسيقى والإخراج، الموسيقى وتصميم المناظر، الموسيقى والميزانسين، الموسيقى والسيناريو، الموسيقى والإعداد

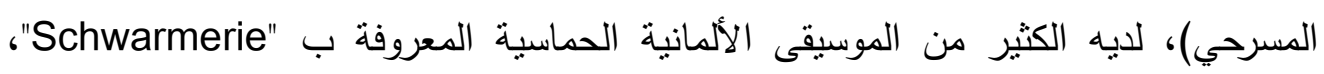
ويقوم بتحليل دقيق للتقافة الفرنسية مبيناً كيف يمكن للموسيقى الألمانية إثارة الطبيعة الدينية

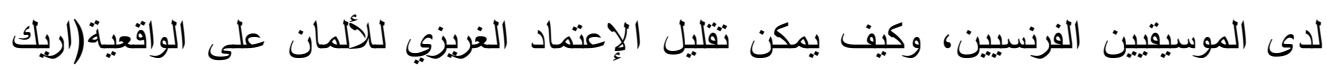

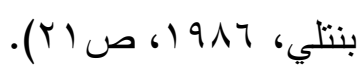

يرى أن الموسيقى تسنظيع تتظيم عناصر العرض المشهدي كلها في وحدة إنسجامية

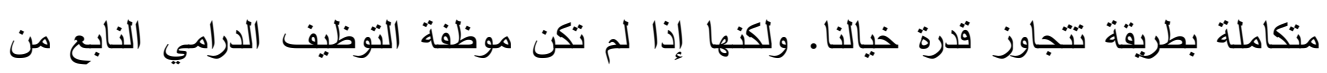

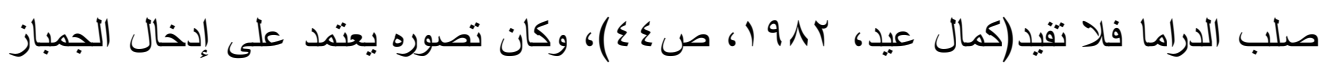
الموسيقي في فن التمثيل لتصبح الموسيقى هي التي تتحكم بتعبير الممثل وليس الكلمة،

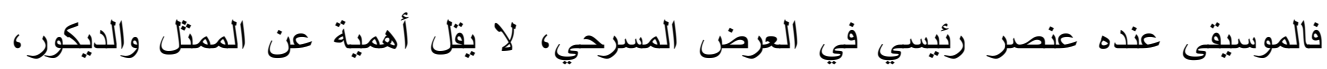

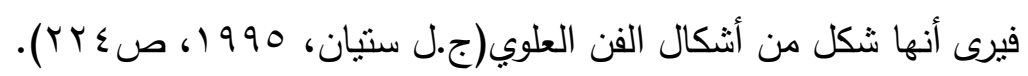

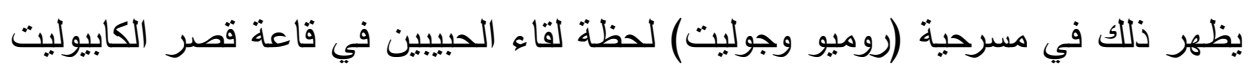

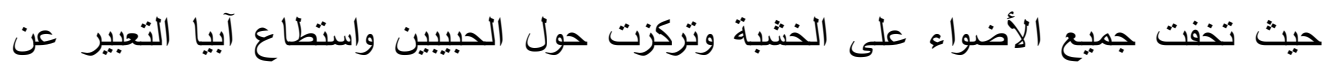

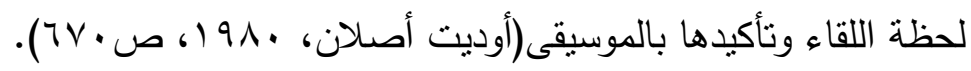
كانت خلفيته عن المسرح والسينوغرافيا من منطلق كونه مشاهد للاراما الموسيقية لريتشارد فاجنر، والمادية الواقعية لسينوغرافيا فاجنر في "festspielb" في بايرويث هي التي إختارها 
كأرض لعرض طلباته الخاصة بالرفض والإصلاح، وكانت سينوغرافياته لدراما فاجنر

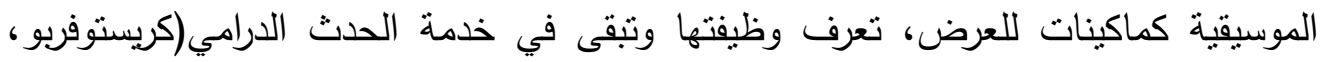

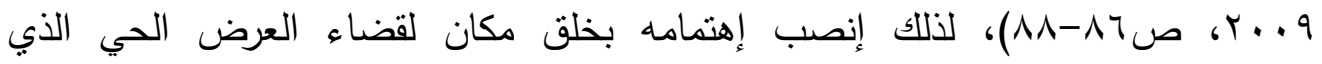
كان ييحث عنه، كانت أفكاره عن السينوغرافيا براها معظم قادة فناني المسرح في هان أوروبا، وكانت ردود أفعالهم متحمسة، وكان هناك مدح خاص لمشاهد أوبرا جلوك "Eurgdice and Orpheus" المادي في الوقت والفضاء الذي حدده آبيا في "musik und Inszenie rung"" عام

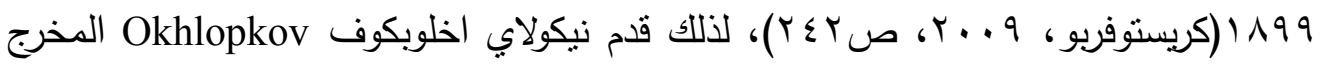
الواقعي في المسرح الروسي في بداية عام • ب9 ا تجربة مسرحية في صالة مستطيلة الثكل،

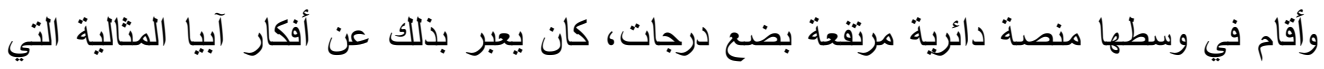
تدعو إلى التخلص من القوالب القديمة للفضاء المسرحي(Richard and Helen, 1984, p.18). بين آبيا لريتشارد فاجنر الذي كان أول من دعا إلى التكامل بين جميع فنون المسرح،

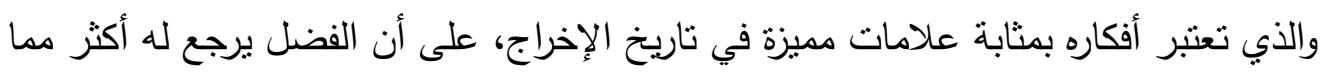
يرجع إلى فاجنر في تحديد معالم النظرية القائلة بضرورة إمتزاج المناظر والإضاءة والإهيل التمثيل والموسيقى وغيرها من العناصر في وحدة عضوية، وكان يحس على ضرورة تجسيم المناظر

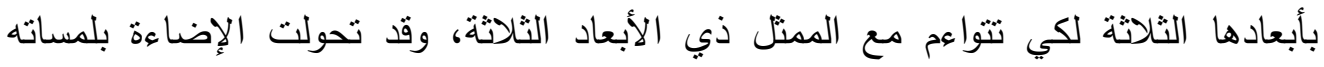

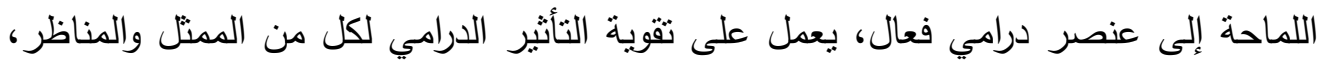

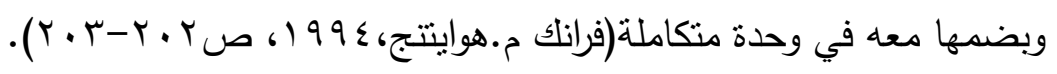

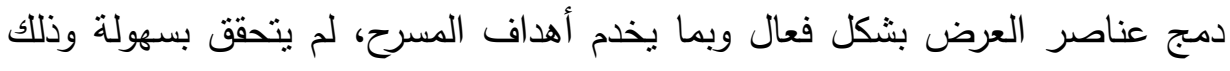

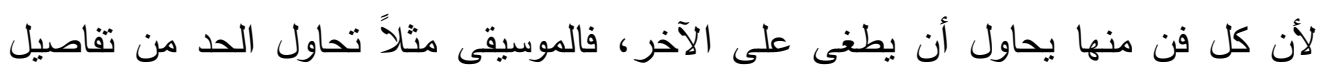

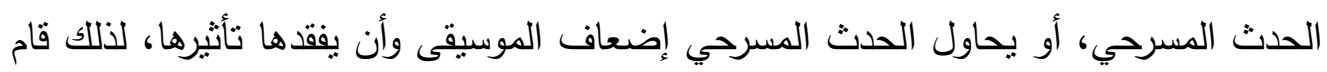

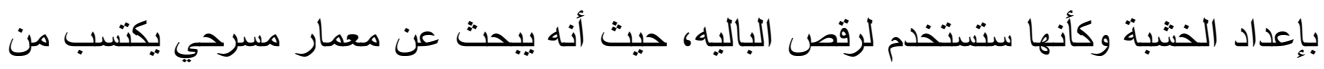

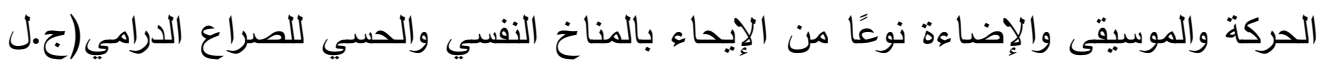

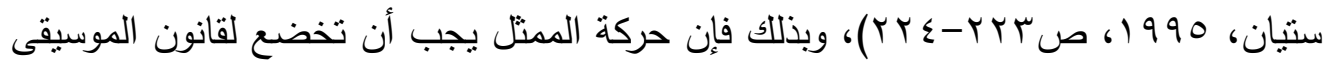
حيث الوفاق بين الزمان والمكان، والإضاءة تحول الفراغ المسرحي بمستويه الأفقي والرأسي إلى عالم حسي موحد - وفاق بين الزمان والمكان - فالإضاءة والموسيقى فقط هما المعبران عن كافة المظاهر، والممثل عنصر من عناصر التركيبة الثناعرية النابعة من التفاعل بين 
حركة الجسد الحي وحركة الديكور والإضاءة وتكملها الموسيقى(سعد أردش، 991، ص. (1) (1) (1) (1) (1) يرى أنه لابد من وضع المنظر المدهون في مكان قائم على الخشبة يسمح للإضاءة بأن

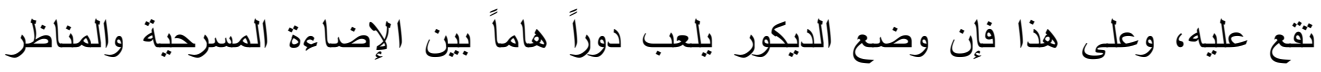

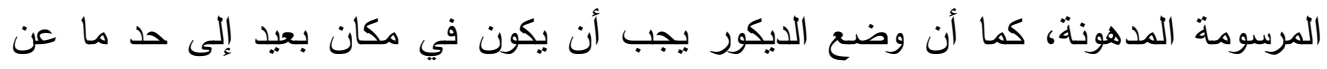

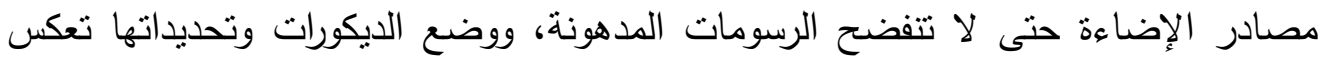

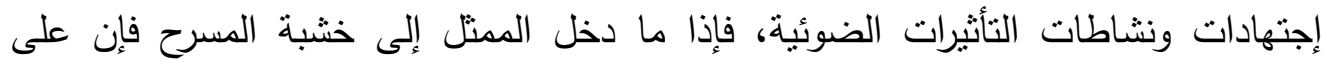
الإضاءة والديكور ، أن يكونا في خدمته من أجل الحصول على وحدة فنبة تؤكد العلاقة العامة

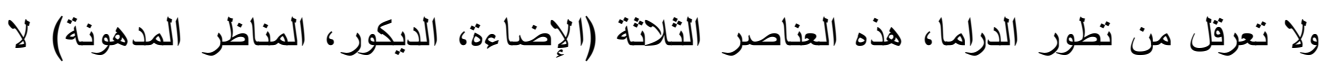
يمكن أن تعمل وحدها في تكوين مستقل لكل منها، كما لا يمكن أن تتفصل واحدة عن الأخرى الأهره

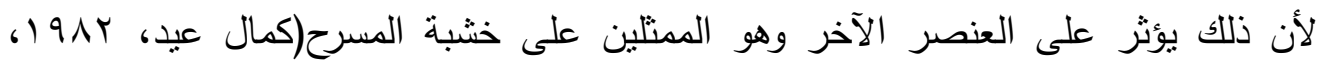
. ص $1 \leqslant$

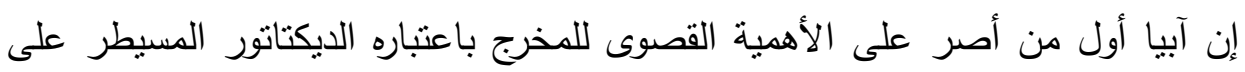

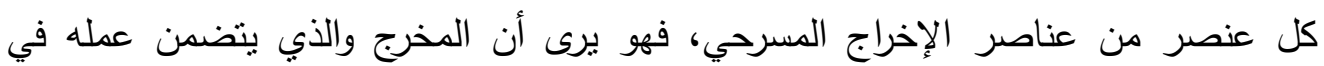
تتظيم الترتيبات المسرحية المتكاملة، يلعب في الدراما الموسيقية الثعرية دوراً سلطوياً، باعنباره الأستاذ المدرب الذي لابد له أن يدرك ما يقتضيه الإعداد المسرحي من دراسة مبدئية، وتوظيف كل عنصر من عناصر الإخراج المشهدي بغية خلق محصلة فنية(اريك بنتلي،

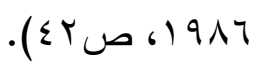

والمخرج يستلهم مكوناته بطريقة تدريجية نتيجة طبيعة عمله، فنجد إستلهام التكوين عند المخرج يختلف عنه عند النحات مثلاً الذي تصل إليه فكرة التكوين دفعة واحدة ثم يبدأ في تحقيقها، أما عند المخرج فرغم وضعه لنفس فكرة التكوين في البداية إلا أن مراحل عمله نتيح

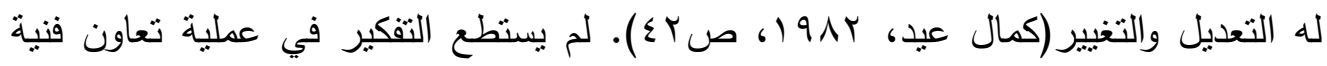

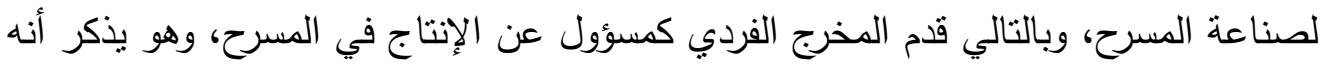

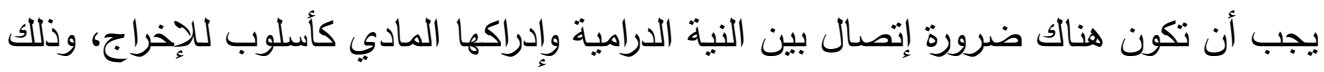
شيء أكثر أساسية من الحاجة إلى العلاقة بين المضمون وشكله، وكان مقتتعاً أن البناء الهرمي المنطقي للإنتاج المسرحي يجب أن ييقى ويجب أن يوجد كفن تعبيري لخلق إدراك حي

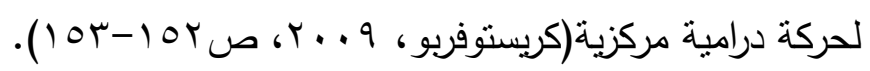




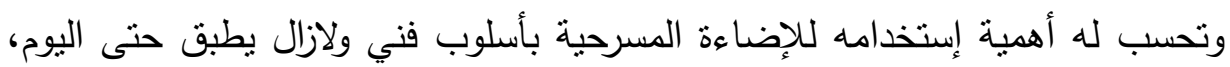

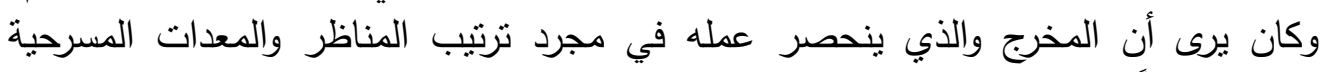

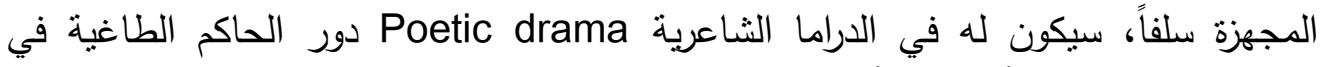

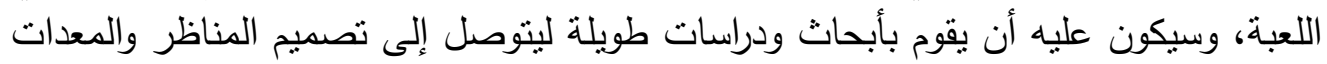

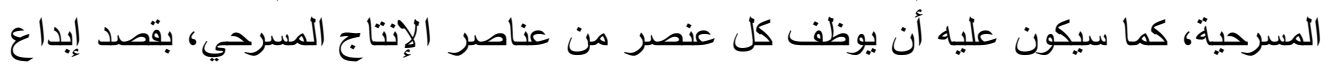

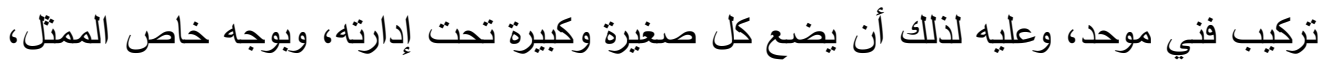

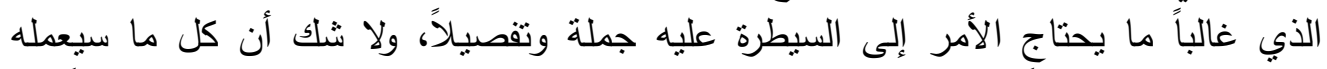

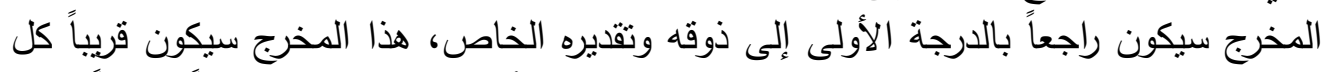

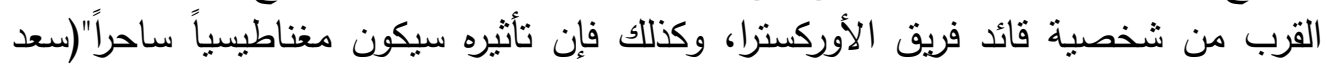

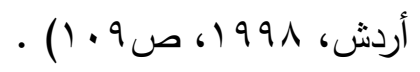

النتائج

وتوصلت الاراسة إلى مجموعة من النتائج أهمها:

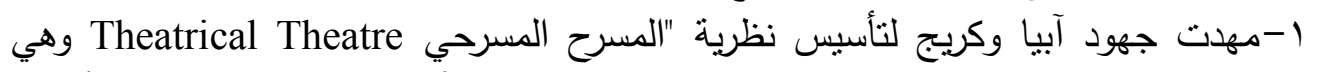

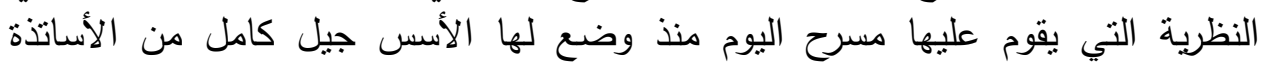

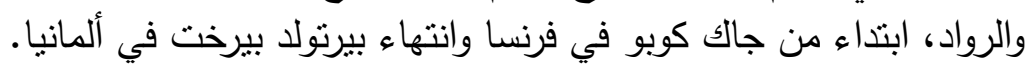

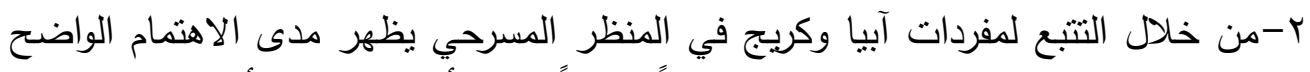

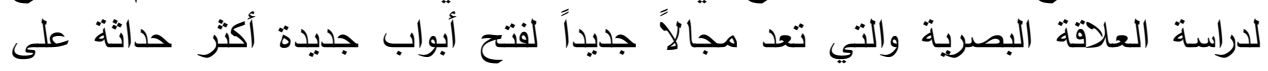

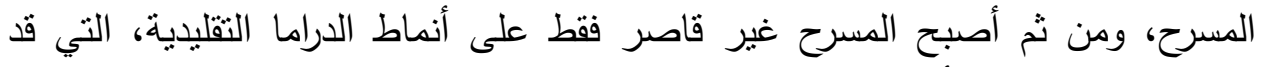

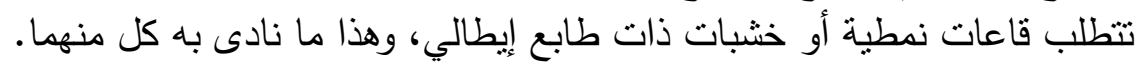

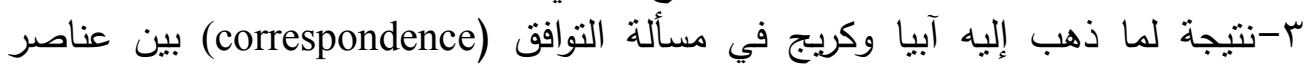

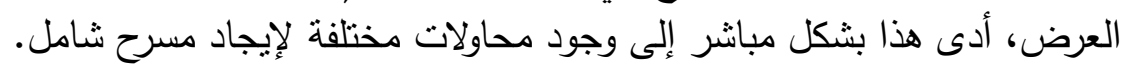

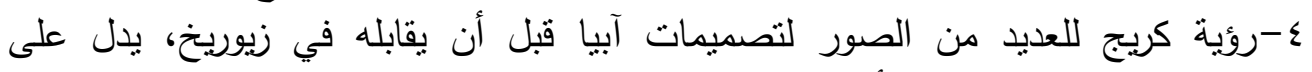

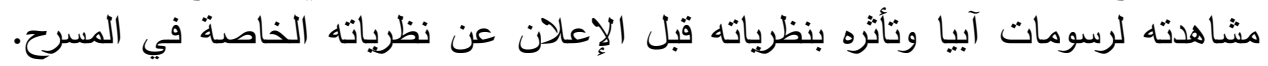

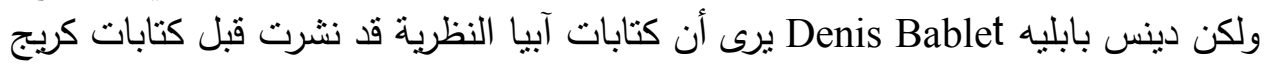

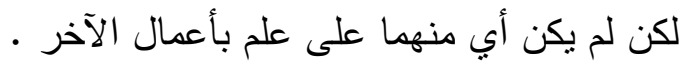
ه-كثيرًا من أفكار آبيا طمست بسبا لفيب نرجمتها الألمانية الغير ملائمة، وساعد ذللك كريج

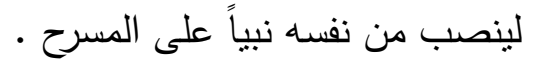

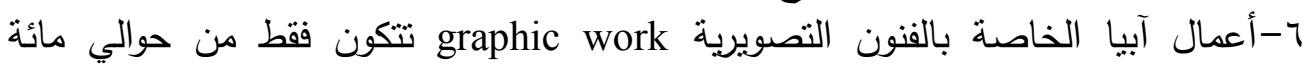

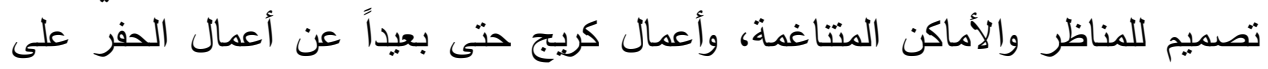

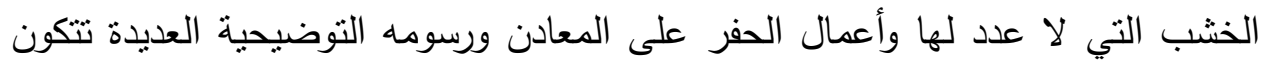

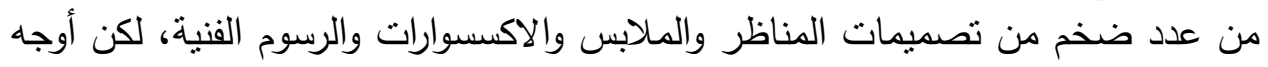
التعارض الأعمق بين كريج وآبيا تتعلق بأمور نظرية. 
أحمد زكي.(919 (1). الإخراج المسرحي دراسة في عبقرية الإبداع المدارس والمناهج. طا. القاهرة. الهيئة المصرية العامة للكتاب.

إريك بنتلي.(719 (1). نظرية المسرح الحديث. ترجمة يوسف عبدالمسيح ثروت. طr. وزارة التقافة والإعلام. العراق. بغداد. دار الثشئون الثقافية العامة.

أمين بكير .(999 (19). في الحرفية المسرحية. القاهرة. الهيئة المصرية العامة للكتاب.

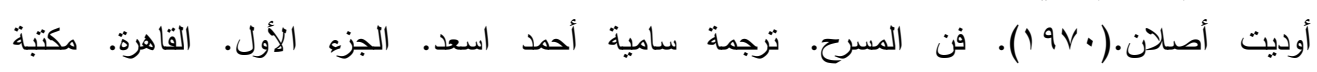
الأنجلو المصرية.

بسنت عبدالحميد محمد.(0 1 ب). الوظيفة الجمالية والدرامية للقناع في المسرح المعاصر . تطبيقاً على أعمال بريخت-جوردن كريج-أوسكار شليمر • رسالة ماجستير • أكاديمية الفنون. المعهد العالي للفنون

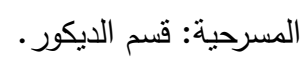

ج.ل سنيان.(9901). الدراما الحديثة بين النظرية والتطبيق. ترجمة محمد جمول. دمشق. منشورات وزارة

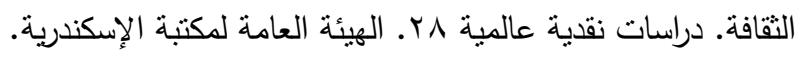

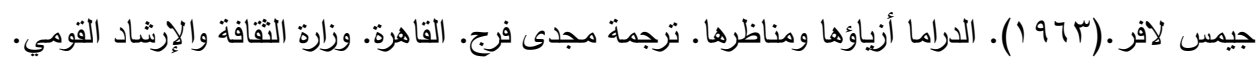
حمادة إبراهيم.(799 (19). العرض المسرحي بين الكلمة واللغات. القاهرة. الهيئة العامة لقصور الثقافة.

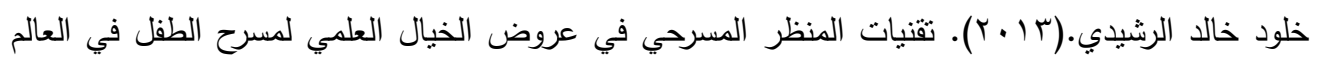

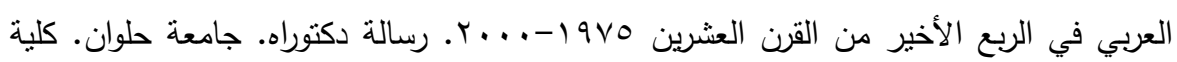

$$
\text { الآداب: قسم علوم المسرح. }
$$

رضوا محمد عبد الحمبد العشماوي.(r(ب). دور فنون التصوير والنحت في إثراء الصورة البصرية للمسرح

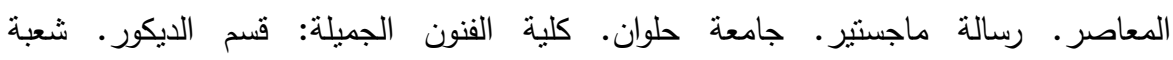

$$
\text { الفنون التعبيرية. }
$$

سعد أردش.(1991 (1). المخرج في المسرح المعاصر ـ الكويت. عالم المعرفة. عباس علي جعفر.(د.ت). القيم الجمالية والفكرية للديكور المسرحي في الاتجاهات المسرحية الحديثة. مجلة

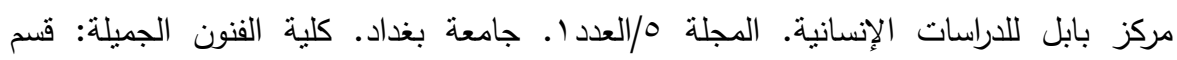

$$
\text { الفنون المسرحي. }
$$

فايز زيد السهيل.(7 ( • ( ). توظيف عنصري الإلقاء والارتجال بين إخراج العروض المسرحية والتليفزيونية في دولة الكويت. رسالة دكتوراه. جامعة حلوان. كلية الآداب: قسم علوم المسرح.

فرانك م.هوايتتج.(ع 99 (). المدخل إلى الفنون المسرحية. نرجمة كامل يوسف وأخرون. مراجعة حسن محمود وسعيد خطاب. تقديم سعيد خطاب. القاهرة. دار المعرفة.

كريستوفربو .(9 . . ץ). المسرح والعرض والتكنولوجيا تطور السينوغرافيا في القرن العشرين. نرجمة هبة عجينة. مراجعة نبيل راغب. مهرجان القاهرة الدولي للمسرح التجريبي. القاهرة. وزارة الثقافة. 


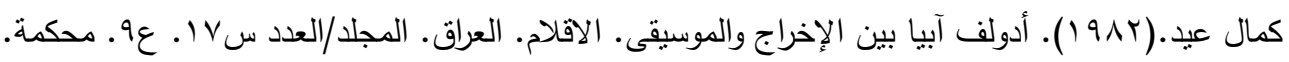

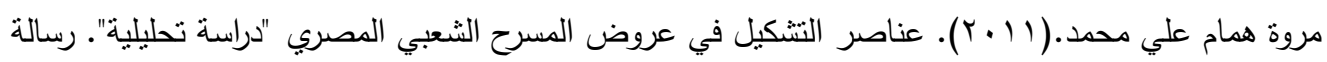
ماجستير • جامعة المنيا. كلية الفنون الجميلة: قسم الديكور . نبيل راغب.(797 (19). النقد الفني. طا ـ القاهرة. الثركة الهصرية العالمية للنشر - لونجمان.

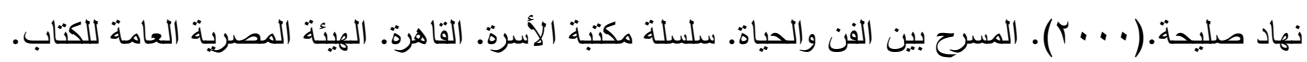

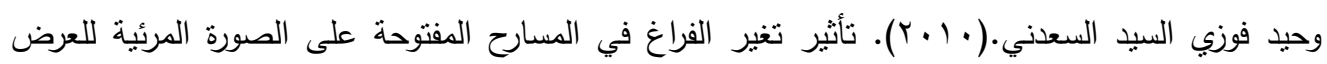

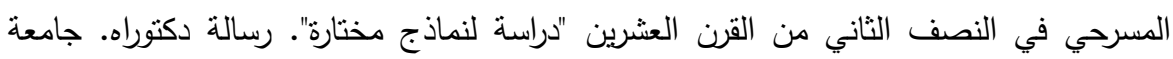
حلوان. كلية الآداب: قسم علوم المسرح. شعبة الديكور.

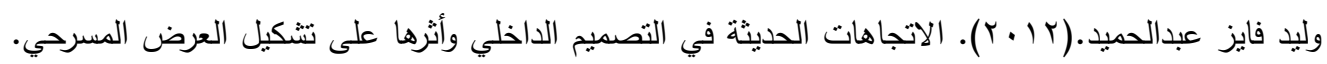

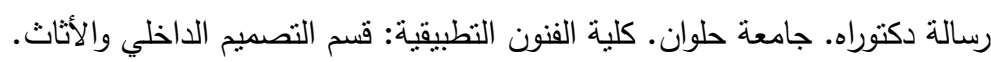

Lee Simonson.(1932). Appia's Contribution to the Modem Stage. Theatre Arts Monthly. XVI. no.8.

Mahmoud Hammam.(1988). Rhythmic space and rhythmic movement: The Adolphe Appia/Jaques-Dalcroze collaboration. The Ohio State University.

Richard and Helen Leacroft.(1984). Theatreland Playhouse an illustrated survy of theatre building from ancient Greece to the present day. Methuen London and New York. first published. 